\title{
- Observed Temperature Changes in the Troposphere and Stratosphere from 1979 to 2018
}

\author{
A. K. Steiner, ${ }^{\mathrm{a}, \mathrm{b}}$ F. LAdstÄdter, ${ }^{\mathrm{a}, \mathrm{b}}$ W. J. RAndel,${ }^{\mathrm{c}}$ A. C. MAYCOCK, ${ }^{\mathrm{d}}$ Q. Fu, ${ }^{\mathrm{e}}$ C. Claud, ${ }^{\mathrm{f}}$ \\ H. Gleisner,,${ }^{\mathrm{g}}$ L. Haimberger,${ }^{\mathrm{h}}$ S.-P. Ho, ${ }^{\mathrm{i}}$ P. KeCKhUt ${ }^{\mathrm{j}}{ }^{\mathrm{T}}$. Leblanc, ${ }^{\mathrm{k}}$ C. MeArs, ${ }^{1}$ L. M. Polvani ${ }^{\mathrm{m}}$ \\ B. D. SANTER,${ }^{\mathrm{n}}$ T. SCHMIDT, ${ }^{\mathrm{o}}$ V. SOFIEVA, ${ }^{\mathrm{p}}$ R. WING ${ }^{\mathrm{j}}$ AND C.-Z. ZOU ${ }^{\mathrm{q}}$ \\ ${ }^{\text {a }}$ Wegener Center for Climate and Global Change, University of Graz, Graz, Austria \\ ${ }^{\mathrm{b}}$ Institute for Geophysics, Astrophysics, and Meteorology, Institute of Physics, University of Graz, Graz, Austria \\ ${ }^{\mathrm{c}}$ National Center for Atmospheric Research, Boulder, Colorado \\ ${ }^{\mathrm{d}}$ School of Earth and Environment, University of Leeds, Leeds, United Kingdom \\ ${ }^{\mathrm{e}}$ Department of Atmospheric Sciences, University of Washington, Seattle, Washington \\ ${ }^{\mathrm{f}}$ Laboratoire de Météorologie Dynamique, Ecole Polytechnique, CNRS/INSU, Palaiseau, France \\ ${ }^{\mathrm{g}}$ Danish Meteorological Institute, Copenhagen, Denmark \\ ${ }^{\mathrm{h}}$ Department of Meteorology and Geophysics, University of Vienna, Vienna, Austria \\ ${ }^{\text {i } C e n t e r ~ f o r ~ W e a t h e r ~ a n d ~ C l i m a t e ~ P r e d i c t i o n, ~ N E S D I S / S T A R / S M C D, ~ C o l l e g e ~ P a r k, ~ M a r y l a n d ~}$ \\ ${ }^{\mathrm{j}}$ LATMOS/IPSL, UVSQ Université Paris-Saclay, Sorbonne Université, CNRS, Guyancourt, France \\ ${ }^{\mathrm{k}}$ Jet Propulsion Laboratory, California Institute of Technology, Wrightwood, California \\ ${ }^{1}$ Remote Sensing Systems, Santa Rosa, California \\ ${ }^{\mathrm{m}}$ Department of Applied Physics and Applied Mathematics, Columbia University, New York, New York \\ ${ }^{\mathrm{n}}$ Program for Climate Model Diagnosis and Intercomparison, Lawrence Livermore National Laboratory, Livermore, \\ California \\ ${ }^{\circ}$ Helmholtz Centre Potsdam, GFZ German Research Centre for Geosciences, Potsdam, Germany \\ ${ }^{\mathrm{p}}$ Finnish Meteorological Institute, Helsinki, Finland \\ ${ }^{\mathrm{q}}$ Center for Satellite Applications and Research, NOAA/NESDIS, College Park, Maryland
}

(Manuscript received 27 December 2019, in final form 12 May 2020)

\begin{abstract}
Temperature observations of the upper-air atmosphere are now available for more than 40 years from both ground- and satellite-based observing systems. Recent years have seen substantial improvements in reducing long-standing discrepancies among datasets through major reprocessing efforts. The advent of radio occultation (RO) observations in 2001 has led to further improvements in vertically resolved temperature measurements, enabling a detailed analysis of upper-troposphere/lower-stratosphere trends. This paper presents the current state of atmospheric temperature trends from the latest available observational records. We analyze observations from merged operational satellite measurements, radiosondes, lidars, and RO, spanning a vertical range from the lower troposphere to the upper stratosphere. The focus is on assessing climate trends and on identifying the degree of consistency among the observational systems. The results show a robust cooling of the stratosphere of about $1-3 \mathrm{~K}$, and a robust warming of the troposphere of about $0.6-0.8 \mathrm{~K}$ over the last four decades (19792018). Consistent results are found between the satellite-based layer-average temperatures and vertically resolved radiosonde records. The overall latitude-altitude trend patterns are consistent between RO and radiosonde records. Significant warming of the troposphere is evident in the RO measurements available after 2001 , with trends of $0.25-0.35 \mathrm{~K}$ per decade. Amplified warming in the tropical upper-troposphere compared to surface trends for 2002-18 is found based on RO and radiosonde records, in approximate agreement with moist adiabatic lapse rate theory. The consistency of trend results from the latest upper-air datasets will help to improve understanding of climate changes and their drivers.
\end{abstract}

¿ Denotes content that is immediately available upon publication as open access.

Corresponding author: A. K. Steiner, andi.steiner@uni-graz.at

This article is licensed under a Creative Commons Attribution 4.0 license (http://creativecommons.org/ licenses/by/4.0/)

DOI: 10.1175/JCLI-D-19-0998.1 


\section{Introduction}

Earth's atmosphere is an essential component of the climate system. Improving knowledge of the natural variability and trends in atmospheric temperature is of vital importance for a better understanding of climate change and its causes. Therefore, consistent long-term observational records of essential climate variables (ECVs), such as upper-air temperature, are required for the detection and attribution of climate change and for verifying climate model simulations.

This topic is a research focus of the international climate science community acting through the World Climate Research Programme (WCRP) and of relevance for the Intergovernmental Panel on Climate Change (IPCC). Sustaining global climate data is the dedicated goal of the World Meteorological Organization (WMO) via the implementation of the Global Climate Observing System (GCOS) based on principles for climate monitoring systems and for the generation of climate data records (CDRs) (GCOS 2011, 2016).

In this context, the activity on Atmospheric Temperature Changes and Their Drivers (ATC) is a long-standing activity within the WCRP/Stratospheric-Tropospheric Processes and Their Role in Climate (SPARC) program. The activity has made substantial contributions to assessments of stratospheric temperature trends, based on analyses of observations and model simulations, with regular contributions to the WMO/United Nations Environment Programme (UNEP) Scientific Assessments of Ozone Depletion (Ramaswamy et al. 2001; Shine et al. 2003; Randel et al. 2009; Thompson et al. 2012; Seidel et al. 2016; Maycock et al. 2018).

Observations from meteorological satellites have become an important source of upper-air data for more than 40 years, while radiosonde measurements from weather balloons are available since the 1950s and earlier. Evaluating long-term temperature changes from these data is challenging, as the instruments were primarily intended for weather observation. Climate monitoring requires higher accuracy (e.g., Karl et al. 2006; Trenberth et al. 2013). Uncertainties due to such factors as instrument changes over time, intersatellite offsets, changes in diurnal sampling, and other modifications in the observational network require homogenization and intercalibration procedures for the construction of CDRs.

Substantial efforts have been put into the reconciliation of atmospheric temperature trends from different observational platforms (e.g., Karl et al. 2006; Randel et al. 2009). Homogenized radiosonde data (e.g., Titchner et al. 2009; Haimberger et al. 2008, 2012) and calibrated records from microwave soundings (e.g., Christy et al. 2007; Mears and Wentz 2009a,b; Zou et al. 2009) confirmed tropospheric warming and stratospheric cooling since the mid-twentieth century. In the low-to-midtroposphere, temperature trends from independent observations and models were found to be consistent, but differences remained in the upper troposphere and stratosphere (e.g., Fu et al. 2011; Mitchell et al. 2013; Lott et al. 2013). Independent observational temperature estimates from the Stratospheric Sounding Unit (SSU) showed large discrepancies and also differed from model trends (Thompson et al. 2012).

There has been substantial interest in comparisons of modeled and observed tropospheric temperature trends. Basic theory of moist adiabatic processes predicts larger warming in the tropical free troposphere compared to near the surface, referred to as tropical tropospheric amplification (Stone and Carlson 1979). A number of previous studies have found that most observational datasets appear to show weaker tropical tropospheric amplification for decadal-scale trends, while this remains a robust feature across several generations of model simulations (Santer et al. 2005, 2008; Po-Chedley and Fu 2012a; Santer et al. 2017b). While various homogenization efforts and reprocessing activities have generally reduced the observation-model differences, the trend amplification estimates from radiosondes and most reprocessed microwave sounding satellite products generally remain smaller than those from climate models and moist adiabatic lapse rate considerations (Thorne et al. 2011; Mitchell et al. 2013). Factors to consider when interpreting model-observation differences include possible errors in climate model forcings (Solomon et al. 2011, 2012; Mitchell et al. 2013; Sherwood and Nishant 2015; Santer et al. 2017a), differences between simulated and observed sea surface temperature (SST) trend patterns (Mitchell et al. 2013; Kamae et al. 2015; Tuel 2019), internal variability (Suárez-Gutiérrez et al. 2017; Kamae et al. 2015; Santer et al. 2019), and, for satellite retrievals, effects from broad vertical weighting functions (Santer et al. 2017b).

While the vertical profile of temperature trends is an important fingerprint of climate change (e.g., Santer et al. 2013), the magnitude and vertical structure of trends is often dependent on details of the datasets and homogenization details (Hartmann et al. 2013), "limiting the ability to draw robust and consistent inferences about the true long-term trends." The IPCC Fifth Assessment Report (Hartmann et al. 2013) stated that this was a key uncertainty:

There is only medium to low confidence in the rate of change of tropospheric warming and its vertical structure. Estimates of tropospheric warming rates encompass surface temperature warming rate estimates. There is low confidence in the rate and vertical structure of the stratospheric cooling. 
Despite these uncertainties, it remains difficult to explain the observed pattern of stratospheric and tropospheric temperature change without anthropogenic forcing (Ramaswamy et al. 2006; Santer et al. 2013; Lott et al. 2013).

In recent years, substantial efforts have resulted in further improvements to layer-averaged temperatures from microwave sounding unit observations (Po-Chedley and $\mathrm{Fu}$ 2012b; Po-Chedley et al. 2015; Mears and Wentz 2016, 2017; Spencer et al. 2017; Zou et al. 2018). Several merged satellite-based datasets have been constructed for providing continuous climate records in the stratosphere from 1979 to the present (McLandress et al. 2015; Zou and Qian 2016; Randel et al. 2016). Revisiting and reprocessing of stratospheric observations (Zou et al. 2014; Nash and Saunders 2015) led to improved consistency of the revised data versions; however, some differences remain (Seidel et al. 2016). Stratospheric temperature trends from the reprocessed observations and from new models of the SPARC Chemistry Climate Model Initiative (CCMI) showed substantial improvement in the agreement between modeled and observed trends, mainly due to updates of the satellite observations. The range of simulated trends was similar to that in the previous generation of models (Maycock et al. 2018; Karpechko et al. 2019).

The work of Maycock et al. (2018) also contributed to the recent Ozone Assessment Report (WMO 2018; Karpechko et al. 2019). Results confirmed a cooling of the stratosphere and an increase in stratospheric cooling with height; this effect is mainly due to increasing greenhouse gases and is modulated by evolving ozone changes. In the upper stratosphere, both greenhouse gases and ozone were found to contribute to the cooling, whereas in the midstratosphere, greenhouse gases are found to be dominant. In the lower stratosphere, ozone depletion was found to be the dominant factor for the cooling until the mid-1990s. Observed stratospheric cooling trends are weaker since around 1998 (Randel et al. 2016; Seidel et al. 2016; Zou and Qian 2016; Randel et al. 2017), reflecting a decline of ozone-depleting substances and the onset of recovery of the ozone layer (e.g., Harris et al. 2015; Solomon et al. 2016, 2017).

Vertical profiles of atmospheric temperature are available from limb-viewing satellite sounders and from groundbased observations, specifically radiosonde and lidar measurements. Reference radiosonde stations have been established over the past decade within the GCOS Reference Upper Air Network (GRUAN), adhering to the GCOS climate monitoring principles (e.g., Seidel et al. 2009; Bodeker et al. 2016). However, such series are still too short for trend retrievals. Gridded radiosonde records (Haimberger et al. 2012) have been updated recently, as well as observations from light detection and ranging (lidar) instruments (e.g., Keckhut et al. 2004; Wing et al. 2018a).
Since 2001, emerging novel satellite-based observations from Global Positioning System (GPS) radio occultation (RO), generically termed Global Navigation Satellite System (GNSS) RO, have become available for atmospheric and climate studies (e.g., Anthes 2011; Steiner et al. 2011, 2020; Ho et al. 2017, 2020) and have been identified as a key component for the GCOS (GCOS 2011). These long-term stable observations provide profile information with high vertical resolution in the upper troposphere and lower stratosphere and are well suited for climate studies (Lackner et al. 2011; Steiner et al. 2009, 2011).

We have deliberately chosen not to include reanalysis datasets in this study. While we acknowledge the high value of these products, we chose to compare observational records that are as independent of each other as possible. Since reanalyses strive to assimilate all available data sources, reanalysis products depend on all those datasets and details of the assimilation systems determine whether a reanalysis draws to one dataset more than to another. Several state-of-the-art reanalyses are currently available or in production (Fujiwara et al. 2017; Hersbach et al. 2020; Simmons et al. 2020).

In this study, we present the latest observational estimates of tropospheric and stratospheric temperature trends based on updated climate records, including novel GNSS RO satellite observations. These estimates include information from gridded radiosonde records and from lidar instruments. We provide an overview of presently available atmospheric observations and recent advances in their development, as well as some of the limitations of the datasets. We discuss variability and trends in both layer-averaged temperatures and vertically resolved data, as well as the associated uncertainties in these results. We also examine the representation of tropical tropospheric amplification in the observations. See the appendix for a list of acronyms used throughout this paper.

\section{Observational datasets}

We begin with a brief description of the observational data that are used for temperature trend analyses and discuss advantages and limitations of the data records.

\section{a. Satellite-based observations}

Instruments flown on polar-orbiting satellites of the National Oceanic and Atmospheric Administration (NOAA) provide the longest-running records of remotely sensed temperatures. These instruments include the Microwave Sounding Unit (MSU), the Advanced Microwave Sounding Unit (AMSU), and the SSU. SSU measurements are available from late 1978 to 2006 and are the only long-term temperature record in the mid-upper stratosphere with global coverage. The MSU instrument provided data from 
TABLE 1. Overview on observational datasets, version, time period, horizontal format, references. Datasets in italics are discussed but not used in the analysis.

\begin{tabular}{|c|c|c|c|c|}
\hline Dataset & Version & Period & Format & Reference \\
\hline \multirow[t]{5}{*}{ Radiosondes } & RAOBCORE1.4 & Jan 1958-Dec 2018 & Monthly $10^{\circ} \times 10^{\circ}$ & Haimberger et al. (2012) \\
\hline & $\mathrm{RICH}$ & Jan 1958-Dec 2018 & Monthly $10^{\circ} \times 10^{\circ}$ & Haimberger et al. (2012) \\
\hline & RS Vaisala RS80/90/92/41 & Jan 1995-Dec 2018 & Monthly $10^{\circ}$ zonal mean & Ladstädter et al. (2015) \\
\hline & $R A T P A C-A v 2$ (not used) & Jan 1958-Dec 2018 & Yearly, zonal means & Free et al. (2004) \\
\hline & IUKv2 (not used) & Jan 1958-Dec 2015 & Monthly mean stations & Sherwood and Nishant (2015) \\
\hline \multirow[t]{2}{*}{ SSU } & STAR SSU v2.0 & Nov 1978-Apr 2006 & Monthly $2.5^{\circ} \times 2.5^{\circ}$ & Zou et al. (2014) \\
\hline & UKMO SSU v2 (not used) & Nov 1978-Apr 2006 & 6-monthly global mean & Nash and Saunders (2015) \\
\hline \multirow[t]{2}{*}{ SSU merged } & STAR SSU/AMSU v3.0 & Nov 1978-present & Monthly $2.5^{\circ} \times 2.5^{\circ}$ & Zou and Qian (2016) \\
\hline & Randel SSU/MLS & Nov 1978-Dec 2018 & Monthly $2.5^{\circ}$ zonal mean & Randel et al. (2016) \\
\hline \multirow[t]{5}{*}{ MSU/AMSU } & RSS v4.0 & Dec 1978-present & Monthly $2.5^{\circ} \times 2.5^{\circ}$ & Mears and Wentz (2017) \\
\hline & STAR v4.1 & Nov 1978-present & Monthly $2.5^{\circ} \times 2.5^{\circ}$ & Zou and Wang (2011) \\
\hline & UAH v6.0 & Jan 1979-present & Monthly $2.5^{\circ} \times 2.5^{\circ}$ & Spencer et al. (2017) \\
\hline & STAR TTS (TUT) & Jan 1981-present & Monthly $2.5^{\circ} \times 2.5^{\circ}$ & \\
\hline & RSS TTS (TUT) & Jan 1987-present & Monthly $2.5^{\circ} \times 2.5^{\circ}$ & \\
\hline \multirow[t]{3}{*}{ Radio occultation } & ROMSAF CDR/ICDRv1.0 & Sep 2001-Dec 2018 & Monthly $5^{\circ}$ zonal mean & Gleisner et al. (2020) \\
\hline & WEGC OPSv5.6 & Sep 2001-Dec 2018 & Monthly $5^{\circ}$ zonal mean & Angerer et al. (2017) \\
\hline & UCAR/NOAA & Sep 2001-Dec 2018 & Monthly $5^{\circ}$ zonal mean & $\begin{array}{l}\text { S.-P. Ho and X. Zhou (2020, } \\
\text { unpublished manuscript) }\end{array}$ \\
\hline \multirow[t]{4}{*}{ Lidars } & NDACC/DWD HOH & Jan 1987-present & Station profile & Steinbrecht et al. (2009) \\
\hline & NDACC/LATMOS OHP & Jan 1991-present & Station profile & Keckhut et al. (2004) \\
\hline & NDACC/JPL TMF & Jan 1989-present & Station profile & Leblanc et al. (1998) \\
\hline & NDACC/JPL MLO & Jan 1993-present & Station profile & Leblanc and McDermid (2001) \\
\hline
\end{tabular}

late 1978 until 1998. The follow-up AMSU instrument provides measurements from 1998 to the present. The sensors measure the radiance of Earth in a cross-track geometry and provide information on broad layer-averages of temperature. Information with higher vertical resolution is given by sensors in limb-viewing geometry, which scan the atmosphere in the vertical. Novel data for climate monitoring with long-term stability are available since 2001 from GNSS radio occultation, the latter exploiting atmospheric refraction.

\section{1) MicrowaVE SOUNDING OBSERVATIONS}

MSU and AMSU sounders are available from a suite of satellites that partially overlap in time. These passive microwave radiometers measure the radiance of Earth at microwave frequencies. The thermal emission line of oxygen near $50-60 \mathrm{GHz}$ is used for retrieving atmospheric temperature information since oxygen is well mixed in the atmosphere. Measuring at different frequencies near the oxygen absorption line corresponds to weighting functions peaking at different heights, which provide information on bulk temperatures over a typical vertical width of about $10 \mathrm{~km}$.

The MSU instrument had four different channels delivering temperature information on four thick atmospheric layers until the NOAA-14 satellite ceased in 2005. The AMSU-A instrument began operation in 1998 with a larger number of 15 channels, sampling more atmospheric layers with better resolution. The MSU data record has been extended to the present by using the AMSU-A channels that most closely match the MSU channels from 1979 to the present based on satellites from NOAA TIROS-N through NOAA-19, the National Aeronautics and Space Administration (NASA) Aqua satellite, and the European Meteorological Operational (MetOp) satellite series.

For this study we use MSU-AMSU-A records from three groups: Remote Sensing Systems (RSS, Santa Rosa, California), the Center for Satellite Applications and Research (STAR) of NOAA/National Environmental Satellite, Data, and Information Service (NESDIS, College Park, Maryland), and the University of Alabama (UAH, Huntsville, Alabama). We use the latest versions of MSUAMSU-A climate data products, which include RSS, version 4.0 (RSS 2019; Mears and Wentz 2009a,b, 2016, 2017); STAR, version 4.1 (NOAA STAR 2019; Zou and Wang 2011); and UAH, version 6.0 (UAH 2019; Spencer et al. 2017). Monthly averaged time series and anomaly time series are available at a resolution of $2.5^{\circ} \times 2.5^{\circ}$ in longitude and latitude (Table 1).

The records contain layer-average temperatures computed from single channels from near-nadir views for the midtroposphere (TMT; MSU channel 2/AMSU-A channel 5), the upper troposphere (TUT or TTS or TTP; MSU channel 3/AMSU-A channel 7), and the lower stratosphere (TLS; MSU channel 4/AMSU-A channel 9). The contributions for the temperature averages originate from broad layers peaking near $5 \mathrm{~km}$ for TMT, near $10 \mathrm{~km}$ for TUT, and near $17 \mathrm{~km}$ for TLS (Fig. 1). 


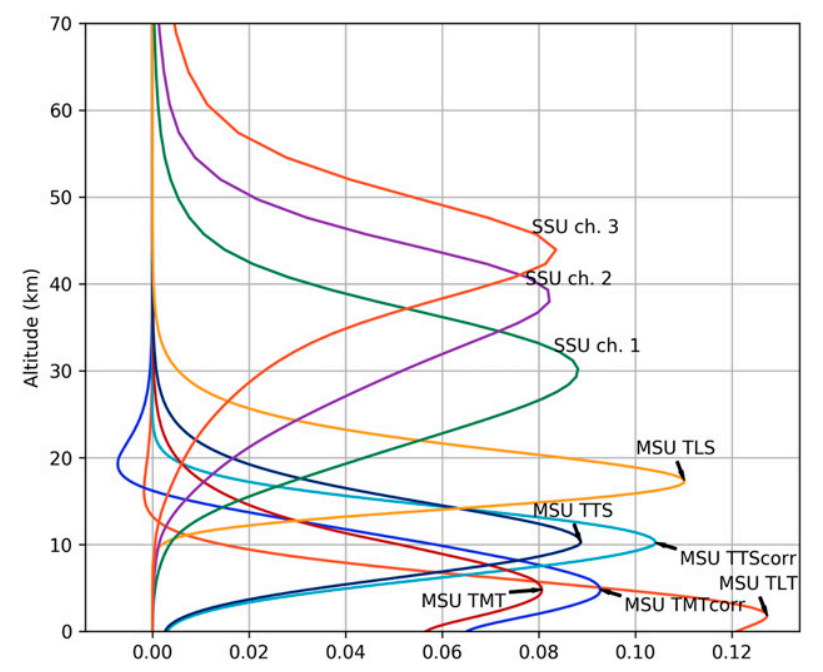

FIG. 1. Vertical weighting functions of stratospheric and tropospheric temperature observations from the SSU (STAR) and MSU (RSS) instruments.

The TMT and TTS weighting functions extend into the stratosphere and contaminate tropospheric information. To accentuate tropospheric information, a TMT corrected temperature (TMTcorr) can be constructed by subtracting the stratospheric contribution from the TMT channel (Fu et al. 2004; Fu and Johanson 2005; Johanson and Fu 2006; Po-Chedley et al. 2015). We computed TMTcorr by a linear combination of TMT and TLS after Johanson and Fu (2006). Similarly, we computed a TTS corrected temperature (TTScorr) by a linear combination of TTS and TLS: $1.18 \times$ TTS $0.18 \times$ TLS.

Additionally, RSS and UAH provide a product for the lower troposphere (TLT) from a weighted average of measurements made at different incidence angles (RSS) or a weighted combination of TMT, TTS, and TLS observations (UAH) to extrapolate MSU channel 2 and AMSU-A channel 5 lower into the lower troposphere, with a peak contribution near $2 \mathrm{~km}$ (Mears and Wentz 2017; Spencer et al. 2017). AMSU-only stratospheric temperature datasets are available from mid-1998 to present from single channels (Wang and Zou 2014).

The merging of MSU and AMSU measurements from many different instruments requires a number of adjustments, since inhomogeneities from different sources can result in spurious trends in retrieved temperatures. Instrument changes over time using different channel frequencies introduce differences due to sampling of slightly different atmospheric layers. Sampling errors occur also from sampling at different local times when satellites are in different orbits. Orbital decay over time can cause brightness temperatures from the near-limb views to warm faster relative to those from the near-nadir views (Wentz and Schabel 1998). The calibration of the electric signal conversion to radiances is also a potential error source when it drifts over time. The absolute calibration uncertainty is estimated to be $0.5-1 \mathrm{~K}$. An overview of known errors is given by Zou et al. (2018).

Over time, the three processing groups developed improved algorithms to account for calibration issues and time-varying biases before the measurements are compiled into a long-term temperature record (Christy et al. 2000, 2003; Mears and Wentz 2009a,b; Zou and Wang 2010, 2011). Mears et al. (2011) performed a detailed uncertainty assessment for RSS data. They discussed uncertainty estimates that arise from the methodological choices in accounting for sampling error, diurnal adjustment, and merging procedures. The different methodological approaches by the processing groups lead to differences in climate data records. However, the latest product versions including improved diurnal drift correction based on observations (Po-Chedley et al. 2015) show much better agreement than the earlier versions (e.g., Seidel et al. 2016; Santer et al. 2017b). Our analyses include each of the datasets to provide a measure of uncertainty due to the differing methodologies.

\section{2) STRATOSPHERIC SOUNDING UNIT AND MERGED DATASETS}

The SSU is a nadir-sounding instrument that flew on NOAA operational satellites from November 1978 to April 2006. The sensor measured the thermal emission of atmospheric carbon dioxide $\left(\mathrm{CO}_{2}\right)$ in the infrared absorption line near $15 \mu \mathrm{m}$. The measurement made use of the pressure modulation technique by putting a cell of $\mathrm{CO}_{2}$ gas in the instrument's optical path. By modulating the gas pressure of the $\mathrm{CO}_{2}$ cell, the single $\mathrm{CO}_{2}$ absorption line was split into three channels with their weighting functions peaking at $30 \mathrm{~km}$ for channel 1 (SSU1), $35 \mathrm{~km}$ for channel 2 (SSU2), and $45 \mathrm{~km}$ for channel 3 (SSU3), respectively. Accordingly, the main contributions for layer-average temperatures stem from heights between 20 and 40, between 25 and 45, and between 35 and $55 \mathrm{~km}$, respectively, spanning the whole stratosphere as illustrated in Fig. 1.

The creation of a consistent homogeneous climate data record from SSU is a challenging task due to several issues and limitations inherent in the SSU measurements that require corrections for radiometric, spectroscopic, and tidal differences (Nash and Saunders 2015). Gas leakage from the onboard $\mathrm{CO}_{2}$ cell caused the cell pressure to decrease, which caused weighting functions to peak at different layers over time. Moreover, the weighting functions were sensitive to $\mathrm{CO}_{2}$ changes in the atmosphere (Shine et al. 2008). Orbital drift also caused 
biases through sampling of the diurnal cycle at different observation times. Detailed descriptions of these issues are provided by Wang et al. (2012), Nash and Saunders (2013, 2015), and Zou et al. (2014).

In recent work, two groups reprocessed all SSU measurements and generated improved CDRs by correcting for $\mathrm{CO}_{2}$ cell pressure changes, satellite orbit drift, changes in atmospheric $\mathrm{CO}_{2}$, and viewing angle differences, and by accounting for the effects of solar diurnal tides in local time sampling. NOAA/STAR provides version STAR SSU v2.0 (NOAA STAR 2019) as monthly means on a $2.5^{\circ} \times 2.5^{\circ}$ latitude and longitude grid (Wang et al. 2012; Zou et al. 2014). The Met Office (Exeter, United Kingdom) provides version UKMO SSU v2.0 only as 6-month-average global means (Nash and Saunders 2015), so that an analysis of latitudinal and seasonal variability is not possible for the UKMO dataset. Comparison of these independently derived versions of SSU show global-mean temperature differences of about $0.5 \mathrm{~K}$, especially from 1979 to 1990 for the upper channels SSU2 and SSU3. A consistency check of SSU data is taking the average of the lowermost channel SSU1 and the uppermost channel SSU3 and subtracting the middle channel SSU2, which should be close to zero. This difference was found to be within $0.2 \mathrm{~K}$ for NOAA/STAR data but much larger for UKMO data (see Fig. 7 in Seidel et al. 2016). We therefore use the STAR SSU v2.0 dataset in the current study.

Several merged data records have been constructed by extending the SSU data, which ended in April 2006, with satellite-based datasets from nadir or limb sounders. These data have higher vertical resolution and are integrated vertically with SSU weighting functions to provide SSUequivalent data that are combined with SSU. McLandress et al. (2015) merged SSU and AMSU data by bridging them with Michelson Interferometer for Passive Atmospheric Sounding (MIPAS) measurements (Fischer et al. 2008). That record is only available until 2012. Randel et al. (2016) have provided a merged SSU record by combining SSU with Microwave Limb Sounder (MLS) data on the Aura satellite. MLS measures microwave emission from $\mathrm{O}_{2}$ and delivers temperatures at $10-90-\mathrm{km}$ altitude with a vertical resolution of about 4-7 km over 20-50 km (Schwartz et al. 2008). Randel et al. (2016) also combined SSU with data from the Sounding of the Atmosphere Using Broadband Emission Radiometry (SABER) instrument based on $\mathrm{CO}_{2}$ emissions, with temperatures retrieved over $16-100 \mathrm{~km}$ and a vertical resolution of $2 \mathrm{~km}$ (Remsberg et al. 2008). Zou and Qian (2016) have derived a merged dataset, STAR SSU-AMSU v3.0, by combining SSU and AMSU measurements with a variational approach for optimally merging the data. In this work, we use those merged SSU records that have been updated to present, that is, STAR
SSU-AMSU v3.0 (NOAA STAR 2019; Zou and Qian 2016) and SSU-MLS (Randel et al. 2016).

In addition to MLS, SABER, and MIPAS, there are other limb-viewing satellite instruments that provide temperature observations with relatively high vertical resolution $(2-4 \mathrm{~km})$. These include the Atmospheric Chemistry Experiment-Fourier Transform Spectrometer (ACE-FTS) from 2004 to the present (Bernath 2017) and the Global Ozone Monitoring by Occultation of Stars (GOMOS) for 2002-12. For GOMOS, two temperature datasets have been released recently: one for the stratosphere (Sofieva et al. 2019), and another dataset for the upper stratosphere and the mesosphere (Hauchecorne et al. 2019). Exploration of these data for potential use in trend analyses is the subject of future research.

\section{3) GNSS RADIO OCCULTATION OBSERVATIONS}

Since 2001, a new type of temperature observation from GNSS RO is available (Anthes 2011). RO is based on the refraction of GNSS radio signals by the atmospheric refractivity field during their propagation to a receiver on a low-Earth orbit satellite. Scanning the atmosphere in limb sounding geometry provides profiles of high vertical resolution of about $100 \mathrm{~m}$ in the troposphere and tropopause, and about $1 \mathrm{~km}$ in the stratosphere (Kursinski et al. 1997; Gorbunov et al. 2004; Zeng et al. 2019). Horizontally, the resolution is about $1.5 \mathrm{~km}$ across ray and ranges from about 60 to $300 \mathrm{~km}$ along ray in the lower troposphere to the stratosphere (Melbourne et al. 1994; Kursinski et al. 1997). The uncertainty of individual RO temperature profiles is about $0.7 \mathrm{~K}$ near the tropopause, gradually increasing into the stratosphere (Scherllin-Pirscher et al. 2011a,b, 2017). For monthly zonal means, the total uncertainty estimate is smaller than $0.15 \mathrm{~K}$ in the upper troposphere and lower stratosphere, and up to $0.6 \mathrm{~K}$ at higher latitudes in wintertime (Scherllin-Pirscher et al. 2011a).

As the time delay measurement of the refracted signals is based on precise atomic clocks, this enables longterm stability and traceability to the Système International (SI) unit of the second (Leroy et al. 2006). Therefore, data from different RO missions can be merged to a seamless record without intercalibration or requiring substantial temporal overlap (Foelsche et al. 2011; Angerer et al. 2017). Continuous observations are available from several RO satellite missions. So far, most missions have used GPS signals at wavelengths of 0.19 and $0.24 \mathrm{~m}$ in the microwave. At these wavelengths, the signals are not affected by clouds and observations are available in nearly all weather conditions. Bending angles are computed from the refracted signals. At high altitudes, the signal-to-noise ratio of the bending angle decreases (above about $50 \mathrm{~km}$ depending on the thermal noise of the receiver) and an initialization of 
bending angle profiles with background information is performed.

Refractivity is computed from bending angle and is related directly to temperature under dry atmospheric conditions. This is the case in the upper tropospherelower stratosphere (UTLS) where water vapor is negligible (Kursinski et al. 1997; Scherllin-Pirscher et al. 2011a). In the moist lower-to-middle troposphere, the retrieval of (physical) atmospheric temperature or humidity requires a priori information in order to resolve the wet-dry ambiguity information inherent in refractivity (e.g., Kursinski et al. 1995; Kursinski and Gebhardt 2014). In this study, we use RO dry temperatures (without a priori information) above $9 \mathrm{~km}$ to avoid the wet-dry ambiguity. For this altitude range, we found that the difference in trends from dry air temperature to trends from a moist retrieval is negligible (not shown).

The data processing adds structural uncertainty to the data as different processing centers use different background information and methods. For the early RO period, based on the single-satellite CHAMP mission only, this uncertainty increases above $25 \mathrm{~km}$ (Ho et al. 2012; Steiner et al. 2013), due to receiver noise and therefore larger impact of the high-altitude bending angle initialization (Leroy et al. 2018). Thus, for climate trend studies, CHAMP is regarded as a limiting factor. In addition, only 150 occultation profiles per day are available from $C H A M P$. However, uncertainty due to the changing number of observations is reduced by correcting for the sampling error in RO climatological fields (Foelsche et al. 2008). For later missions, based on advanced receivers, data are usable to higher altitudes (Steiner et al. 2020). Overall, structural uncertainty in trends is lowest at $8-25-\mathrm{km}$ altitude globally for all inspected RO variables and different missions (Steiner et al. 2020). Data products comprise individual profiles and gridded fields of bending angle, refractivity, pressure, geopotential height, temperature, and specific humidity. These products have been used in a number of different atmosphere and climate studies (Ho et al. 2010; Anthes 2011; Steiner et al. 2011; Ho et al. 2020).

Comparison of Wegener Center (WEGC) RO data against MSU-AMSU records showed slight differences in TLS trends (Steiner et al. 2007; Ladstädter et al. 2011) while good agreement of Radio Occultation Meteorology Satellite Application Facility (ROM SAF) RO stratospheric trends to Aqua AMSU records was found (Khaykin et al. 2017). Comparisons with collocated radiosondes (detailed in the following section), Vaisala RS90/92 and GRUAN, showed very good agreement with global annualmean temperature differences of less than $0.2 \mathrm{~K}$. Radiosonde daytime radiation biases were identified at higher altitudes (Ladstädter et al. 2015; Ho et al. 2017). The stability of RO makes it a useful calibration reference for AMSU (Chen and Zou 2014) and radiosondes (Ho et al. 2017; Tradowsky et al. 2018).

In this work, we use RO data over the period 2002-18, WEGC RO OPS v5.6 of the Wegener Center (Graz, Austria) (EOPAC Team 2019; Angerer et al. 2017), the ROM SAF CDR v1.0 version of ROM SAF [Danish Meteorological Institute (DMI) Copenhagen, Denmark] (ROM SAF 2019; Gleisner et al. 2020), and UCAR/ NOAA data [UCAR COSMIC Data Analysis and Archive Center (CDAAC); Boulder, Colorado, and NOAA] (UCAR CDAAC 2019; S.-P. Ho and X. Zhou 2020, unpublished manuscript). An overview on RO data processing and a description of retrieval steps for each specific dataset is given in Steiner et al. (2020, their Table 1).

\section{b. Ground-based observations}

Ground-based temperature observations are available from radiosonde measurements made with weather balloons. Radiosonde measurements extend into the lower stratosphere only, while lidar measurements extend to the mid- and upper stratosphere. Observations are limited to ground stations and have limited coverage in space and time.

\section{1) RADIOSONDE OBSERVATIONS}

Reliable radiosonde temperature records commenced in 1958. Observations are made once or twice per day at stations that are mainly located on Northern Hemisphere continents. The weather balloons reach up to about $25 \mathrm{~km}$ until they burst. Depending on wind conditions, typical drift distances are a few kilometers in the lower troposphere to about $50 \mathrm{~km}$ in the lower stratosphere (Seidel et al. 2011). All radiosonde datasets have limited coverage in the tropics. Different countries use different instrument types, and instrumentation has changed over time (e.g., Thorne et al. 2011). A further problem is that radiosondes are affected by radiation biases during daytime measurements (Sherwood et al. 2005; Ladstädter et al. 2015). To reduce data discontinuities and residual cooling biases in radiosonde-derived CDRs, a number of different adjustment techniques have been developed.

Several centers have produced homogenized radiosonde products using different methods. NOAA's Radiosonde Atmospheric Temperature Products for Assessing Climate (RATPAC) (Free et al. 2004) is based on spatial averages of adjusted temperature data (Lanzante et al. 2003) from 1958 to 1995. Since 1996, it is based on the Integrated Global Radiosonde Archive (IGRA) station data using a first difference method (Free et al. 2004) and the record is not fully homogenized. RATPAC-A, version 2, data (NOAA NCEI 2019) are provided as zonal yearly anomalies. 
The Hadley Centre Atmospheric Temperature dataset (HadAT) from the Met Office (Thorne 2005; McCarthy et al. 2008) uses a larger number of stations; however, it is only available for 1958-2012 and not updated to the present (www.metoffice.gov.uk/hadobs/hadat/). Sherwood et al. (2008) constructed a radiosonde record based on an iterative universal kriging (IUK) method. The record is available only until 2015 and not updated to present (Sherwood and Nishant 2015).

Haimberger et al. (2008) introduced the homogenized Radiosonde Observation using Reanalysis (RAOBCORE) and Radiosonde Innovation Composite Homogenization $(\mathrm{RICH})$ datasets. Break points are determined either by using composites of neighboring observations as reference (RICH) or by comparing to departures from a reanalysis background (RAOBCORE). RICH is independent of the background, but interpolation errors may be large where sampling is sparse such as in the tropics and the Southern Hemisphere. RAOBCORE reduces interpolation errors at the cost of slight background dependence on ERA-Interim (Haimberger et al. 2012). Gridded RAOBCORE and RICH data have been updated to the end of 2018 (Haimberger 2019). The data are provided as monthly means at $10^{\circ} \times 10^{\circ}$ resolution.

Radiosonde temperature data are also available from GRUAN radiosonde stations (https://www.gruan.org/; Bodeker et al. 2016). GRUAN is a reference observing network of quality measurements of ECVs to reduce uncertainty in climate monitoring (Seidel et al. 2009; Thorne et al. 2013). As of 2019, GRUAN comprises of 26 sites, 12 of which have been certified. We do not use GRUAN data because records start in 2009 and are too short for reliable trend estimation.

In this study, we use the RICH and RAOBCORE radiosonde records of the University of Vienna. In addition, we also use radiosonde data from the ERAInterim archive (denoted RS-VAIS), restricting our attention to data from the Vaisala RS80, RS90, RS92, and RS41 radiosondes from 1995 onward. These measurements are known to be of high quality (Steinbrecht et al. 2008; Nash et al. 2011; Ladstädter et al. 2015).

\section{2) LIDAR OBSERVATIONS}

Stratospheric and lower-mesospheric temperature lidar measurements are available at several locations from the Network for the Detection of Atmospheric Composition Change (NDACC). The Rayleigh lidar technique uses molecular backscattering of a pulsed laser beam to derive the vertical profile of atmospheric density. The collected signal is sampled as a function of time, that is, geometric altitude. The intensity of scattered light is directly related to the air density at the backscatter altitude considered. Using a priori temperature information at the top of the profile, temperature can be retrieved with high spatiotemporal resolution from the measured relative density profile (Hauchecorne and Chanin 1980). Accuracy and precision both depend on altitude, and typically range from less than $0.1 \mathrm{~K}$ in the stratosphere to $10 \mathrm{~K}$ or more at the very top of the profile ( $80 \mathrm{~km}$ or higher). Descriptions of the Rayleigh lidar temperature retrieval and its uncertainty can be found in Hauchecorne and Chanin (1980), Keckhut et al. (2011), Leblanc et al. (2016), and Wing et al. (2018a). Validation studies showed that the accuracy of individual lidar profiles is better than $1 \mathrm{~K}$ in the altitude range of $35-65 \mathrm{~km}$ (Keckhut et al. 2004). A variety of studies have assessed stratospheric temperature variability and trends from lidar (e.g., Randel et al. 2009; Steinbrecht et al. 2009; Li et al. 2011; Funatsu et al. 2011, 2016). Lidar temperatures for the stratosphere and mesosphere were used as reference data for detecting biases in satellite-based observations from limb sounders (Wing et al. 2018b).

The Observatoire de Haute Provence (OHP) lidar in southern France $\left(43.94^{\circ} \mathrm{N}, 5.71^{\circ} \mathrm{E}\right)$ is one of the longestrunning lidar stations, commencing measurements in 1979 (Hauchecorne and Keckhut 2019; Keckhut et al. 1993). Further long-term lidar records (NDACC 2019) are available from the Hohenpeissenberg station in Germany $\left(\mathrm{HOH} ; 47.80^{\circ} \mathrm{N}, 11.02^{\circ} \mathrm{E}\right.$ ) since 1987 (Werner et al. 1983) and from the Jet Propulsion Laboratory (JPL) Table Mountain Facility (TMF) in California (TMF, $34.4^{\circ} \mathrm{N}, 117.7^{\circ} \mathrm{W}$ ) since 1988 (Leblanc et al. 1998). In addition, we show data available since 1993 from the JPL lidar at the tropical station of Mauna Loa Observatory (MLO) in Hawaii $\left(19.54^{\circ} \mathrm{N}, 155.58^{\circ} \mathrm{W}\right.$; Leblanc and McDermid 2001). Under clear-sky conditions, lidar temperature measurements are usually made on 5-20 nights per month at each station. These measurements were then averaged to monthly mean time resolution for each station. The time series for OHP, $\mathrm{HOH}, \mathrm{TMF}$, and MLO were analyzed in this study.

\section{Trend analysis}

For estimation of atmospheric trends from observations, we used global-mean and zonal-mean monthly mean temperature time series of layer-average brightness temperatures and of vertically resolved temperature observations. RO and RS-VAIS zonal-mean fields were corrected to account for their incomplete sampling of the full spatial and temporal variability of the atmosphere (Scherllin-Pirscher et al. 2011a; Ladstädter et al. 2015). The sampling error is estimated from the difference between a field of averaged collocated profiles and a full atmospheric field (Foelsche et al. 2008). The 
sampling error is subtracted from the gridded climatologies, leaving a small residual sampling error (ScherllinPirscher et al. 2011a). The atmospheric fields used in this study for estimating the sampling error were reanalysis fields from ERA5.1 (Simmons et al. 2020) for ROM SAF RO, WEGC RO, and RS-VAIS, and ERA-Interim for UCAR RO. RICH and RAOBCORE gridded fields were not corrected for sampling error.

We computed anomaly time series by subtracting the monthly climatology of the common reference period 2002-18 from the absolute time series. Trend estimates were computed for a number of different periods: 19792018, 1979-98, 1999-2018, and 2002-18. Trends were computed by applying a linear ordinary least squares fit as well as by multiple regression analysis. The uncertainty estimates of the trends are expressed as $95 \%$ confidence level, accounting for lag-1 autocorrelation of the regression residuals. Trends are deemed to be "significantly different from zero" if the confidence interval does not contain the null hypothesis value (zero trend).

The multivariate regression model includes a linear trend term and natural variability terms accounting for the solar cycle, El Niño-Southern Oscillation (ENSO), stratospheric volcanic eruptions, and the quasi-biennial oscillation (QBO) (Fig. 2). Commonly used indices describe these terms. Solar variability is represented by the radio emission flux from the sun at a wavelength of $10.7 \mathrm{~cm}$. The period 1979-2018 covers almost four solar cycles. Daily observed solar flux values (Natural Resources Canada 2019) were averaged to monthly means.

ENSO originates in the tropical Pacific Ocean with warm SSTs during El Niño phases and cold anomalies during La Niña phases. It dominates interannual variability in the troposphere up to the lowermost stratosphere. During an El Niño event, the tropical troposphere warms and the lowermost tropical stratosphere cools (Free and Seidel 2009; Randel et al. 2009). Deviations from the zonal mean are seen as eddy signals in the subtropics (Scherllin-Pirscher et al. 2012). We use the Niño-3.4 SST index as an ENSO proxy. This is the spatially averaged SST in the Niño-3.4 region $\left(5^{\circ} \mathrm{S}-5^{\circ} \mathrm{N}\right.$ and $\left.170^{\circ}-120^{\circ} \mathrm{W}\right)$. By definition, El Niño or La Niña periods occur if 5-month running means of SST anomalies in this region exceed $+0.4 \mathrm{~K}$ or $-0.4 \mathrm{~K}$, respectively, for at least six months (Trenberth 1997). Our multiple regression relied on version 5 of the Extended Reconstructed Sea Surface Temperature dataset (ERSSTv5; Huang et al. 2017). To account for lags between this measure of ENSO variability and the response of tropospheric temperature, we used a lag of 3 months for the monthly ERSSTv5 (1981-2010 base period) Niño-3.4 index (CPC 2019).

Tropical stratospheric variability is dominated by the QBO, which has a period of about 28 months. The QBO is characterized by alternating easterly and westerly wind regimes propagating downward to the tropopause at about $1 \mathrm{~km}$ per month. This is also seen in the stratospheric temperature structure as positive and negative temperature anomalies of several degrees; anomalies are proportional to the vertical gradient of the zonal winds (Randel et al. 1999; Baldwin et al. 2001). This distinctive thermal structure makes it possible to investigate the QBO with RO temperature anomalies (Wilhelmsen et al. 2018). Here, we use the QBO index of monthly mean zonal winds of the Freie Universität of Berlin (FU Berlin 2019) produced by combining observations of three radiosonde stations: Canton Island, Gan/Maldives, and Singapore (Naujokat 1986). Applying a principal component analysis to the wind profiles over $70-10 \mathrm{hPa}$, we use the first two orthogonal basis functions, PC1 and PC2, as proxies for the QBO (Wallace et al. 1993).

Explosive volcanic eruptions such as El Chichón in 1982, Mount Pinatubo in 1991 (Robock 2000) and also minor volcanic eruptions after 2000 affect short-term temperature trends in the troposphere and stratosphere (Solomon et al. 2011; Stocker et al. 2019). As a proxy for the effects of volcanic eruptions we compute the stratospheric aerosol optical depth over $15-25 \mathrm{~km}$ from the monthly mean Global Space-Based Stratospheric Aerosol Climatology (GloSSAC), version 1.0, averaging over the tropics and subtropics (Thomason 2017; Thomason et al. 2018).

In addition, we used observed surface temperature trends to compare with trends in the free atmosphere. We employed the HadCRUT4 dataset for this purpose (Met Office and the Climatic Research Unit, University of East Anglia, United Kingdom; HadCRUT4 2020; Morice et al. 2012).

\section{Results}

\section{a. Long-term time series and linear trends}

Here we present multidecadal time series and linear trends over the 40-yr period 1979-2018 for the stratosphere and the troposphere. Results are from SSU and MSU layeraverage temperatures as well as from lidar temperatures. Figure 3 shows near-global-average $\left(85^{\circ} \mathrm{S}-85^{\circ} \mathrm{N}\right)$ anomaly time series of stratospheric temperatures for the lowerstratospheric TLS channel from three MSU-AMSU records and for SSU channels in the mid-upper stratosphere from two merged records, SSU-AMSU and SSU-MLS. Stratospheric temperatures show the impact of the major eruptions of El Chichón in 1982 and Mount Pinatubo in 1991. These large warming signals have peak amplitude in the lower stratosphere and last for roughly two years after the eruptions; only minor TLS changes occurred between the two eruptions. 

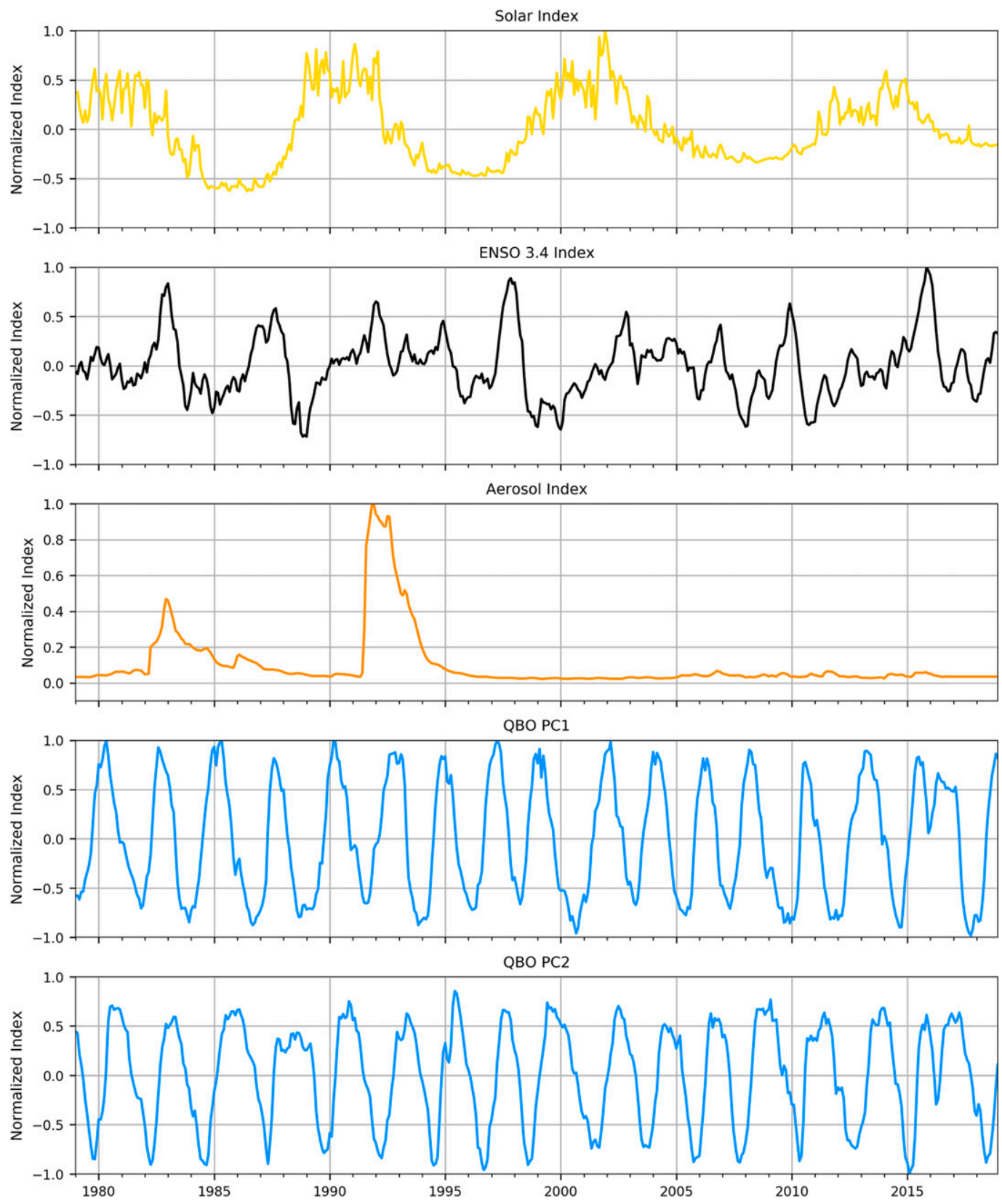

FIG. 2. Normalized indices of atmospheric variability modes used in the multiple regression analysis for 1979-2018 (top to bottom) solar flux, SST Niño-3.4, aerosol index, and the first two principal components PC1 and PC2 of QBO winds.

The linear trend over the last four decades shows cooling of the stratosphere. This is also the case if the anomalous years after the major volcanic eruptions are disregarded in the trend computation, which has minimal impact on trend values but substantially reduces the trend uncertainty (not shown). Accounting for the main modes of natural variability by applying multiple regression analysis also reduces the trend uncertainty with only small impact on trend values. Stratospheric trends increase from the lower stratosphere to the upper stratosphere. For results from the STAR group, for example, the least squares linear trends for the period 19792018 are $-0.25 \pm 0.16 \mathrm{~K}$ decade $^{-1}$ for TLS, and $-0.56 \pm$ $0.13,-0.62 \pm 0.13$, and $-0.70 \pm 0.14 \mathrm{~K}$ decade $^{-1}$ for channels SSU1, SSU2, and SSU3 (respectively; see Fig. 3). The corresponding trends from the multiple regression model, also obtained with STAR data, are $-0.17 \pm 0.08 \mathrm{~K}_{\text {decade }}{ }^{-1}$ for TLS, and $-0.50 \pm 0.09,-0.58 \pm 0.09$, and $-0.67 \pm$ $0.10 \mathrm{~K}_{\text {decade }}{ }^{-1}$ for SSU1, SSU2, and SSU3 (respectively). These results indicate that the long-term trends are robust to 

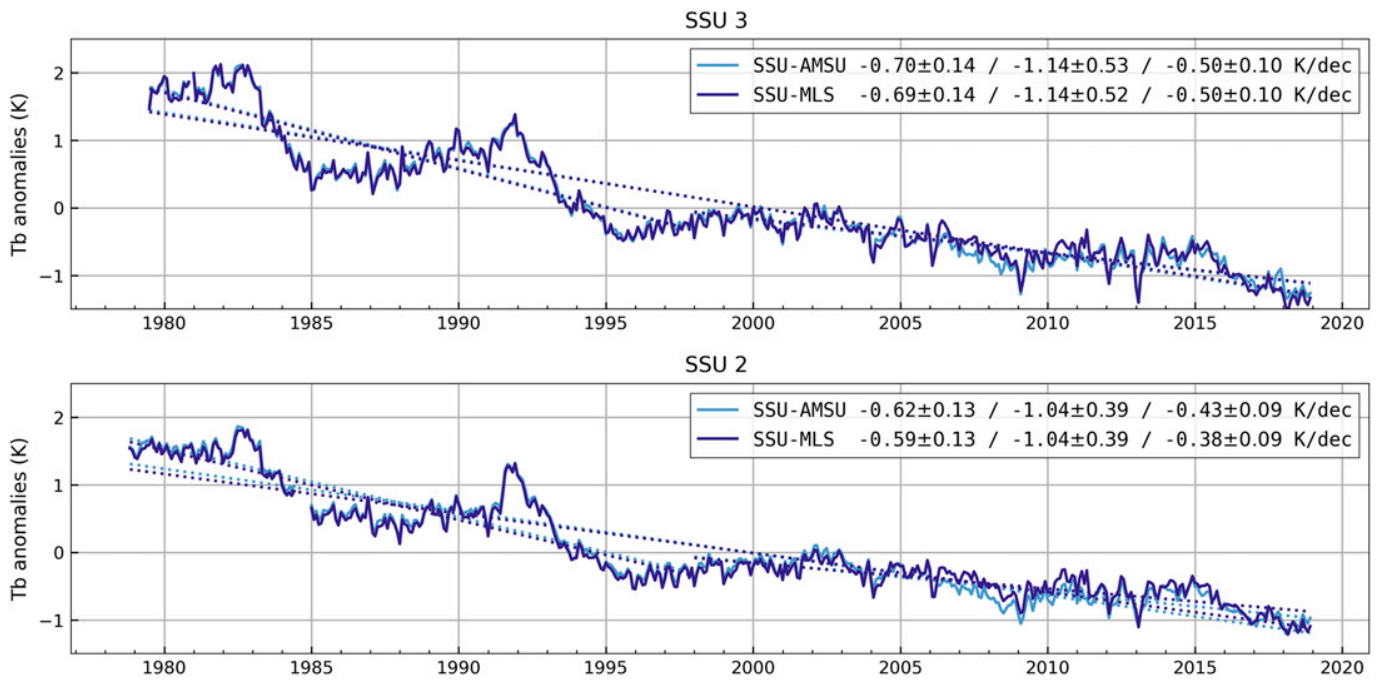

SSU 1

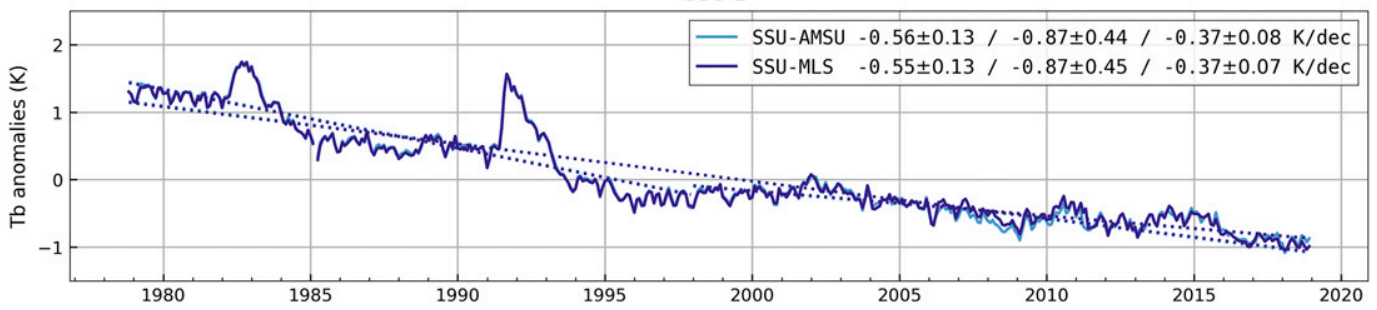

MSU TLS (ch. 4)

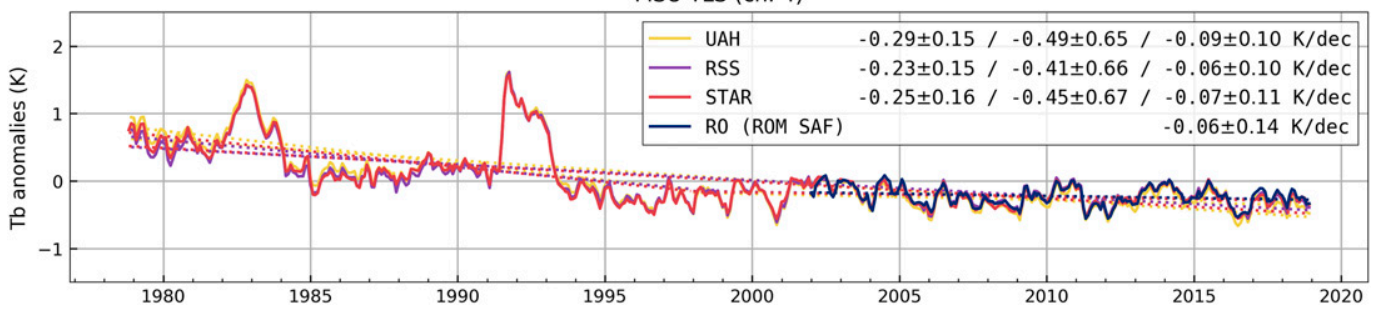

FIG. 3. Stratospheric time series $1979-2018$ and trends of near-global averages $\left(85^{\circ} \mathrm{S}-85^{\circ} \mathrm{N}\right)$ are shown for layer-average brightness temperatures from SSU and MSU records. Shown are (bottom to top) channel MSU TLS (13-22 km), and SSU channels SSU1 $(20-40 \mathrm{~km})$, SSU2 $(25-45 \mathrm{~km})$, and SSU3 $(35-55 \mathrm{~km})$. Data records from different centers are displayed, SSUAMSU and SSU-MLS, as well as TLS from three centers RSS, STAR, and UAH. The temperature anomalies are plotted with respect to the period for 1980-2018. Overplotted are equivalent TLS brightness temperatures from RO since 2001 for comparison (anomalies mapped with reference period 1980-2018 minus 2002-18 from RSS). Linear trends are indicated for the full period and for split trends 1979-97 and 1998-2018 (except RO for September 2001-December 2018). Trend values are given in this order (left to right).

the statistical methodology used for fitting trends. The implied trend uncertainty is smaller in the multiple regression analysis, although some degree of collinearity between several of the predictor variables (see Fig. 2) can hamper assessment of trend uncertainty (Santer et al. 2001). All trends are significant at the 95\% level, and results from different research groups are reasonable consistent.

The overall decrease in stratospheric temperature is about 1-3 K over the last four decades, but the characteristics change over time and as a function of atmospheric layer.
Cooling is larger in the first half of the record. The amplitude of trends decreases since the late 1990s, particularly in the lowermost stratosphere. This nonlinear behavior in TLS is due to the decline of stratospheric ozone in the early period (Ramaswamy et al. 2001) and ozone recovery after roughly 1998 due to the effectiveness of the Montreal Protocol (WMO 2018). These results are consistent with a number of previous studies (e.g., Randel et al. 2009, 2016; Seidel et al. 2016; Zou and Qian 2016; Randel et al. 2017; Polvani et al. 2017; Solomon et al. 2017; Maycock et al. 2018). Interestingly, 

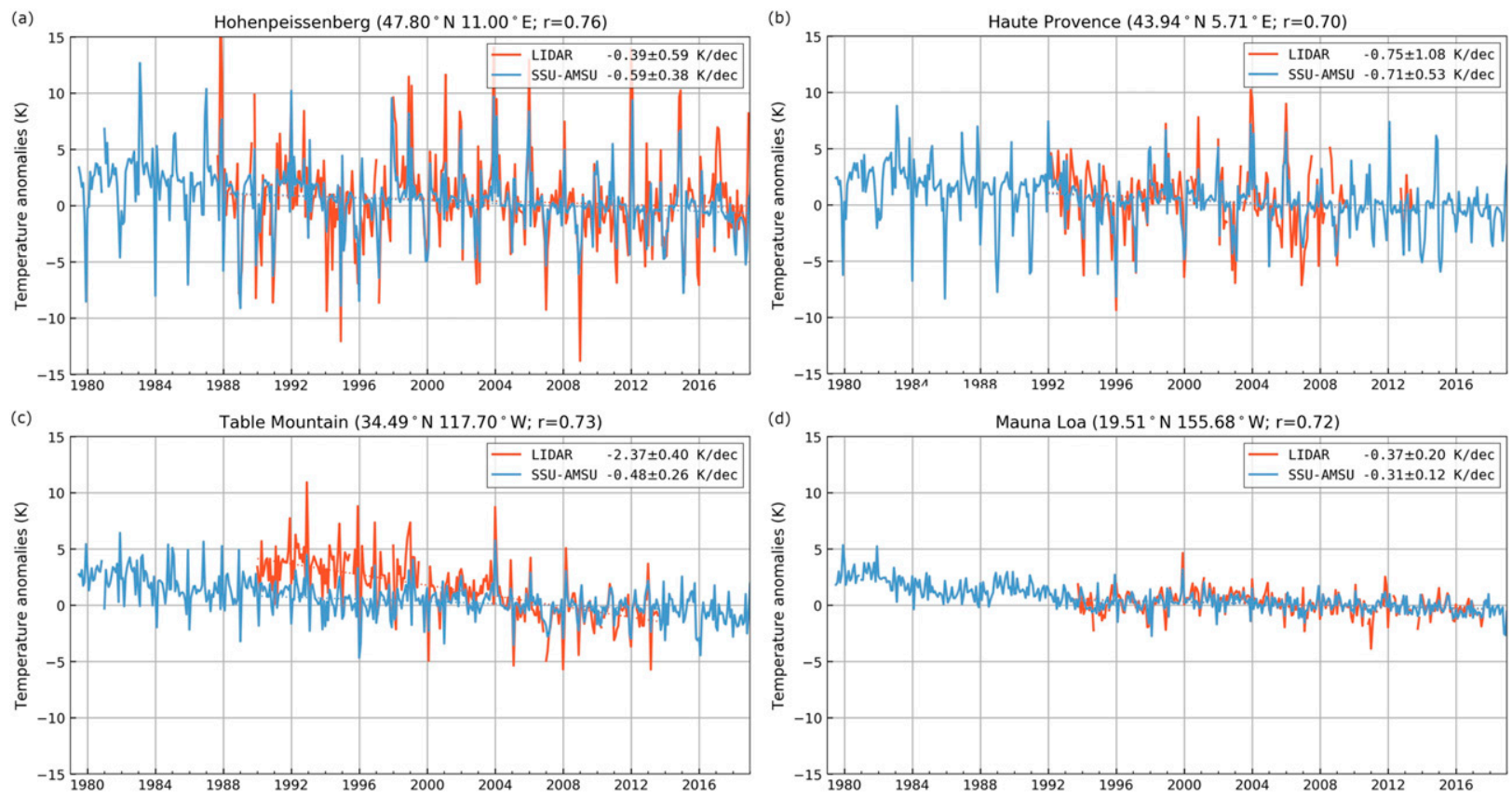

FIG. 4. Stratospheric time series from four lidar stations in the form of SSU3 equivalents compared to collocated SSU3 time series from SSU-AMSU. Shown are lidar temperature anomalies for the stations (a) HOH, (b) OHP, (c) TMF, and (d) MLO. Linear trends for the respective time periods are indicated as well.

since about 2015 the cooling seems to be enhanced, which may be related to the onset of solar minimum conditions.

Lidar time series (Fig. 4) are the only long-term temperature series in the stratosphere suitable for comparison to SSU temperatures. Monthly mean temperature time series from the four selected lidar stations are presented. Equivalent temperatures have been computed from lidar profiles using the SSU3 weighting function from STAR, by sampling and weighting the lidar temperature at the respective height levels (ftp:/ftp.star.nesdis.noaa.gov/ $\mathrm{pub} / \mathrm{smcd} / \mathrm{emb} / \mathrm{mscat} / \mathrm{data} / \mathrm{SSU} / \mathrm{SSU}$ _v2.0/Weighting Function/). The vertically weighted lidar results are compared to collocated SSU3 data at grid points corresponding to the location of the respective lidar stations. A constraint in this comparison is the limited temporal sampling of the lidars at individual stations (measurements are limited to clear nights) in contrast to the full monthly sampling of SSU. This may partly explain the larger variability of the lidar temperature series.

In general, the variability in lidar temperatures is higher at the more northerly $\mathrm{HOH}$ and OHP stations $\left(47.8^{\circ}\right.$ and $44^{\circ} \mathrm{N}$, respectively) and smaller for the tropical MLO station $\left(19.5^{\circ} \mathrm{N}\right)$. Lidar temperature anomalies are well correlated with the SSU3 time series: correlations are $0.76,0.70,0.73$, and 0.72 for SSU-AMSU versus $\mathrm{HOH}$, OHP, TMF, and MLO (respectively). All linear trends in Fig. 4, both for the lidar data and SSU, were computed for the time periods dictated by the length of individual lidar records. At $\mathrm{HOH}$, the linear trend of $-0.39 \pm 0.59 \mathrm{~K} \mathrm{decade}^{-1}$ for the lidar is smaller than the trend of $-0.59 \pm 0.38 \mathrm{~K}$ decade $^{-1}$ for SSU-AMSU (Fig. 4a). Although the latter is statistically significant, the trend in $\mathrm{HOH}$ lidar data is not significant because of the larger variability of lidar data. At TMF, the lidar trends are larger than SSU trends, specifically due to the differences in the first half of the time series. These differences are likely associated with a warm temperature bias in the first few years of the lidar record. The warm bias was caused by the presence of signal-induced noise in the raw lidar data complicating the extraction of background noise. The pre-1996 temperature data at TMF should therefore be considered with caution. A full reanalysis of these data is currently being undertaken, with the expectation of a more accurate TMF record during these early years. At OHP, lidar trends are of a similar magnitude as SSU-AMSU trends over the time period considered, but these are not statistically significant due to the large variability. Note that data at the end of the OHP time series are not included in this work as they are currently being investigated for biases. For the MLO station, there is very close agreement between the lidar trend of $-0.37 \pm 0.20 \mathrm{~K} \mathrm{decade}^{-1}$ and the SSU-AMSU trend of $-0.31 \pm 0.12 \mathrm{~K}_{\text {decade }}{ }^{-1}$.

Tropospheric temperature anomalies are shown in Fig. 5 based on time series of MSU-AMSU layer-average temperature anomalies. As expected, the interannual 

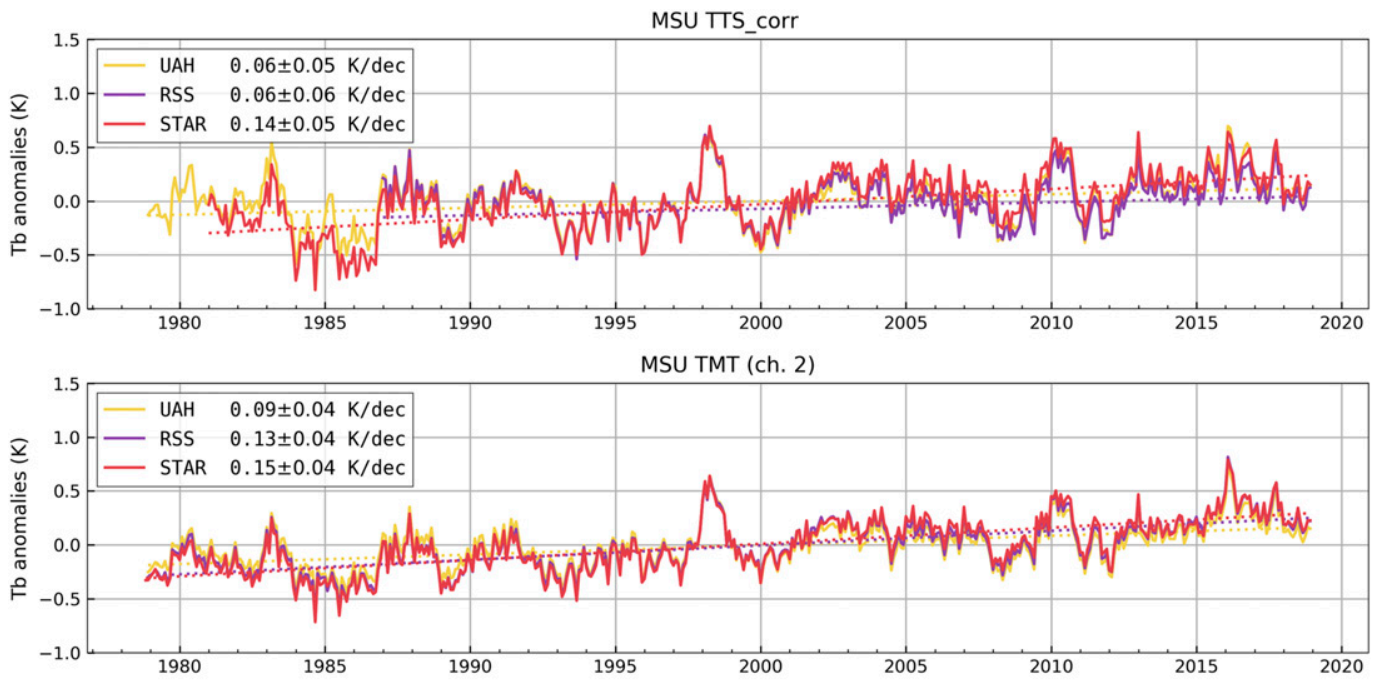

MSU TMT_corr
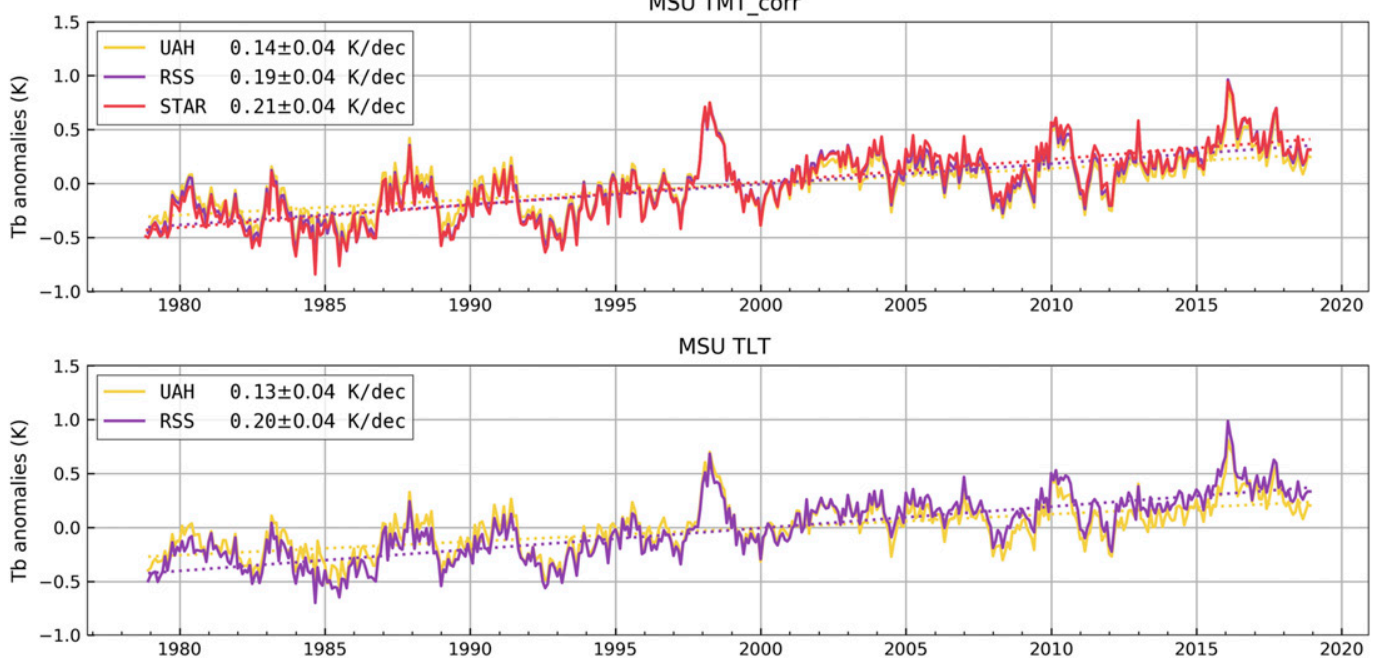

FIG. 5. Tropospheric time series $1979-2018$ and trends of near-global averages $\left(85^{\circ} \mathrm{S}-85^{\circ} \mathrm{N}\right)$ are shown for layeraverage brightness temperatures from MSU records. Shown are MSU channels (bottom to top) TLT, TMTcorr, TMT, and TTScorr, peaking at about 2, 5, 5, and $10 \mathrm{~km}$, respectively. Data records from different centers are displayed for RSS, STAR, and UAH. Linear trends are indicated for the period 1979-2018 (except TTScorr: STAR for 1981-2018, RSS for 1987-2018). The temperature anomalies are plotted with respect to the period for 1980-2018.

variability is strongly correlated with ENSO behavior-for example, positive tropospheric temperature anomalies coincide with El Niño events in 1983, 1997, 2010, and 2016. Statistically significant warming trends are detected over the last four decades in the lower troposphere (TLT), over the total troposphere (TMTcorr), and, to a lesser amount, for TTScorr. The trend is weaker for the unadjusted midtroposphere channel (TMT) because it contains information from cooling of the stratosphere. The upper-troposphere channel TTS (see Fig. 1) also reaches into the lower stratosphere (to about $20 \mathrm{~km}$ above Earth's surface) and therefore integrates over tropospheric warming and stratospheric cooling; this results in a near-zero trend (not shown).
Note that the TTS time series of RSS starts in 1987, and is therefore shorter than the TLT, TMT, TMTcorr, and TTS records.

The warming of the troposphere is about $0.6-0.8 \mathrm{~K}$ over the last four decades (Fig. 5). The RSS least squares linear trend for TMTcorr $\left(0.19 \pm 0.04 \mathrm{~K} \mathrm{decade}{ }^{-1}\right)$ is similar to the trend obtained from multiple linear regression of $\left(0.16 \pm 0.02 \mathrm{~K} \mathrm{decade}^{-1}\right)$. Trend values are lowest for the UAH record (see, e.g., Santer et al. 2017a,b).

\section{b. Latitude structure of trends}

We used multiple regression to calculate trends as a function of latitude for $10^{\circ}$ zonal bands. The latitudinal 
structure of stratospheric trends (Fig. 6a) shows a consistent picture of cooling over all latitudes that increases with height. Cooling is statistically significant in all four stratospheric layers and at all latitudes, except poleward of $\sim 50^{\circ} \mathrm{S}$ and $50^{\circ} \mathrm{N}$ for TLS and at very high latitudes in the Southern Hemisphere for the SSU channels. Trends range from approximately $-0.25 \mathrm{~K} \mathrm{decade}^{-1}$ in the lower stratosphere (TLS) to -0.5 to $-0.7 \mathrm{~K} \mathrm{decade}^{-1}$ in the midupper stratosphere (SSU1 to SSU3). At northern high latitudes, cooling is up to $-1 \mathrm{~K}$ decade $^{-1}$ in the uppermost SSU channel while at southern high latitudes it is weaker. In the lower stratosphere, the latitudinal trend structure is different from the upper stratosphere, with largest cooling at high latitudes in the Southern Hemisphere and smallest cooling over the northern polar region. This structure in TLS trends arises because the strengthening of the Brewer-Dobson circulation (BDC) over 1979-2018 leads to cooling at low latitudes and high-latitude warming. The BDC partly compensates for the radiative cooling associated with high-latitude ozone depletion, especially in the Southern Hemisphere (Fu et al. 2015, 2019). Both ozone and atmospheric circulation changes are important factors in determining the latitudinal pattern of the lower-stratospheric cooling trend (e.g., Solomon et al. 2017; Maycock et al. 2018). In addition, an enhanced lower-stratospheric cooling is seen in the midlatitudes (Fu et al. 2006), which is caused by the poleward shift of subtropical jets associated with tropical expansion (Fu and Lin 2011; Polvani et al. 2017; Maycock et al. 2018).

Tropospheric trends (Fig. 6b) show significant warming over all latitudes from the lower troposphere to the midtroposphere (channels TLT, TMTcorr, TMT), except at southern high latitudes where the trend is near zero. At northern high latitudes, warming trends are largest and reach about $0.3-0.5 \mathrm{~K}$ decade $^{-1}$. TTScorr shows significant trends only in the tropics. Although RSS and UAH have large differences in TLT trends in this region, both products clearly show significant tropical warming. Only channel TTS shows near-zero trends that can be explained by the broad weighting function, which receives contributions from both tropospheric warming and lower-stratospheric cooling (see Fig. 1).

We also calculated zonal-mean trends for the period 2002-18 (Fig. 7), thus facilitating direct comparison with GNSS RO observations. Stratospheric trends (Fig. 7a) show larger uncertainties than were evident for the 19792018 period, particularly at high latitudes. This is due to combined effects of the large dynamical variability and the shorter analysis period. In the lowermost stratosphere, the trend over all latitudes is near zero except at southern high latitudes, where it reaches $-1 \mathrm{~K}$ decade $^{-1}$. This result is highly dependent on the end points of the short data record, as Antarctic TLS trends beginning in 1998 are positive (Randel et al. 2017), while trends beginning in 2000 or 2002 are negative (Fu et al. 2019; Fig. 7); the results are strongly influenced by the Antarctic stratospheric warming in 2002 (e.g., Newman and Nash 2005). This sensitivity highlights the uncertainty of polar stratospheric trends derived from short data records with arbitrary end points. Note that Antarctic ozone has been recovering since the late 1990s (Solomon et al. 2017), leading to radiative heating within the background of large dynamic variability. In the mid and upper stratosphere, cooling trends are found to be significant over $50^{\circ} \mathrm{S}-50^{\circ} \mathrm{N}$. Almost all TLS trends over 2002-18 fail to achieve statistical significance.

Tropospheric trends for the period 2002-18 (Fig. 7b) show a latitudinal structure similar to that found over the full 1979-2018 period, with significant trends throughout most of the tropics and subtropics. At high latitudes, however, trends have large uncertainties and are not significant.

\section{c. Vertically resolved trends}

Vertically resolved trends from radiosonde data in Fig. 8 are presented for the period 1979-2018 together with trends from layer-average temperatures from MSUAMSU and merged SSU records. This provides an overview of upper-air trends from the lower troposphere to the stratopause for near-global averages $\left(70^{\circ} \mathrm{S}-70^{\circ} \mathrm{N}\right)$ (Fig. 8a) and for the tropics $\left(20^{\circ} \mathrm{S}-20^{\circ} \mathrm{N}\right)$ (Fig. 8b). Overall, the different records show remarkably good agreement. Surface temperature trends are also indicated and are similar to TLT trends.

Global-mean temperature trends from the homogenized, gridded RICH and RAOBCORE radiosonde records are plotted at standard pressure levels and show warming of near $0.2 \mathrm{~K} \mathrm{decade}^{-1}$ in the lower and midtroposphere (from $0.15 \pm 0.03 \mathrm{~K}$ to $0.19 \pm 0.03 \mathrm{~K} \mathrm{decade}^{-1}$ at 5-9 km). Close agreement of radiosondes with layer averages of MSU-AMSU is found for TLT and TMTcorr, except in the case of UAH satellite data (which has less warming than the RSS and STAR MSU-AMSU products).

In the lower stratosphere, cooling rates inferred from radiosonde records range from about -0.2 to $-0.4 \mathrm{~K}$ decade ${ }^{-1}$ (from $-0.26 \pm 0.09$ to $-0.39 \pm 0.06 \mathrm{~K} \mathrm{decade}^{-1}$ ). In the mid-upper stratosphere, the radiosonde-estimated cooling increases from -0.5 to $-0.7 \mathrm{~K} \mathrm{decade}^{-1}$ (from $-0.52 \pm 0.05$ to $-0.68 \pm 0.07 \mathrm{~K} \mathrm{decade}^{-1}$ ), in close accord with merged SSU records.

Tropical average trends (Fig. 8b) show a similar structure to the near-global mean $\left(70^{\circ} \mathrm{S}-70^{\circ} \mathrm{N}\right)$. As expected, the trend uncertainties are slightly larger because tropical variability is larger than for near-global averages. Tropospheric warming rates are about $0.15 \mathrm{~K}$ decade $^{-1}$ (from $0.12 \pm 0.04$ to $0.18 \pm 0.03 \mathrm{~K} \mathrm{decade}^{-1}$ ) from radiosondes and correspond well with MSU-AMSU TLT 
(a) SSU 3; 1979-01 to 2018-12

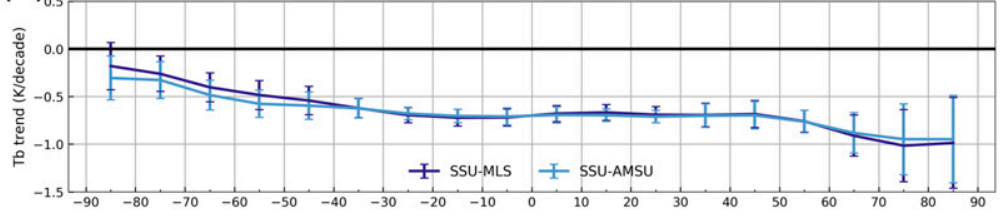

SSU 2; 1979-01 to 2018-12
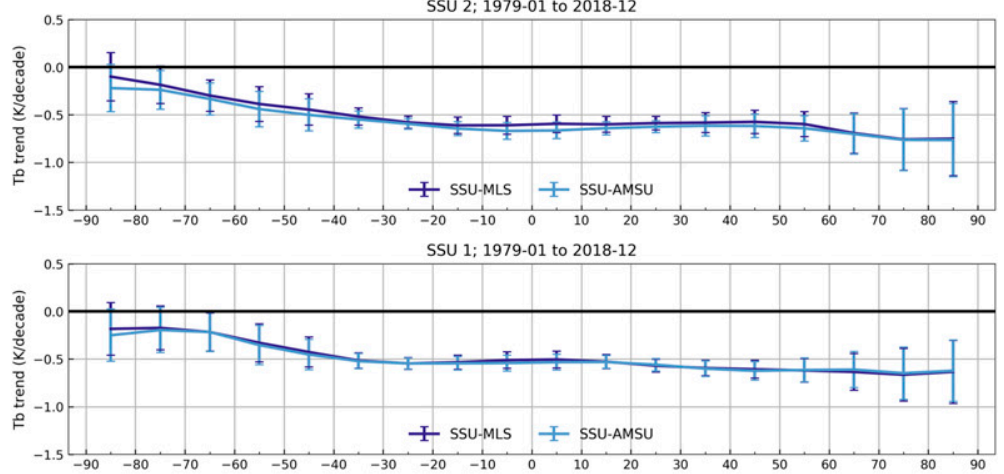
MSU TLS (ch. 4); $1979-01$ to 2018-12

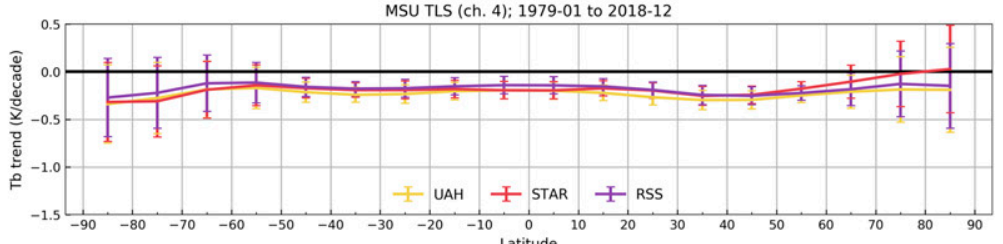

(b)

MSU TTS_corr; $1979-01$ to 2018-12

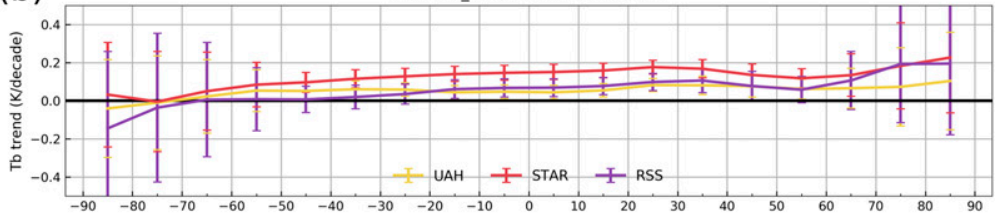
MSU TMT (ch. 2); $1979-01$ to 2018-12

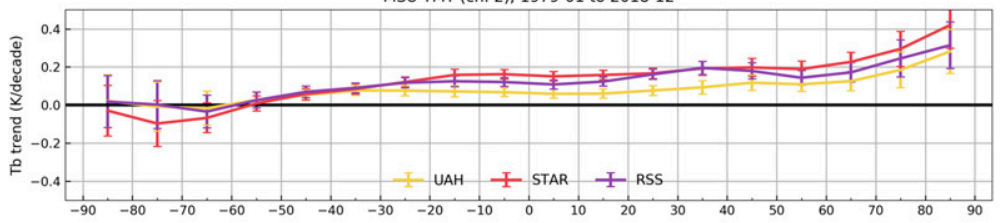

MSU TMT_corr; $1979-01$ to 2018-12

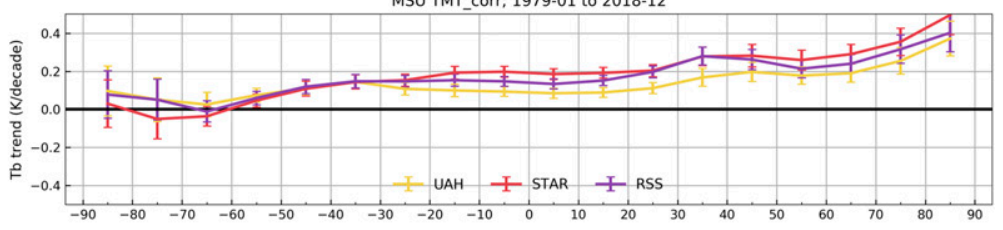

MSU TLT: $1979-01$ to $2018-12$

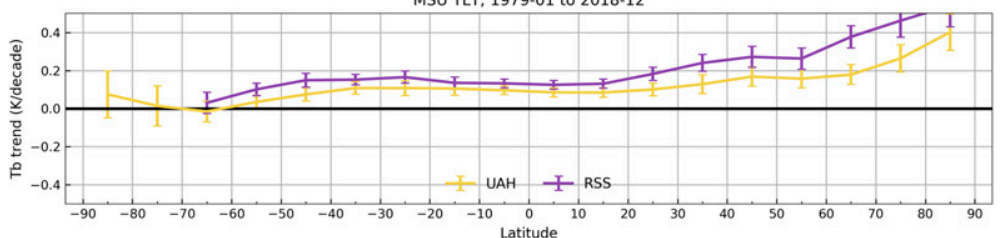

FIG. 6. Latitude structure of trends 1979-2018 for (a) stratospheric channels MSU TLS $(13-22 \mathrm{~km})$, SSU1 $(20-40 \mathrm{~km})$, SSU2 $(25-45 \mathrm{~km})$, and SSU3 $(35-55 \mathrm{~km})$; and (b) tropospheric channels MSU TLT, TMTcorr, TMT, and TTScorr (except RSS TTScorr for 1987-2018), respectively. 
(a) SSU 3; 2002-01 to 2018-12
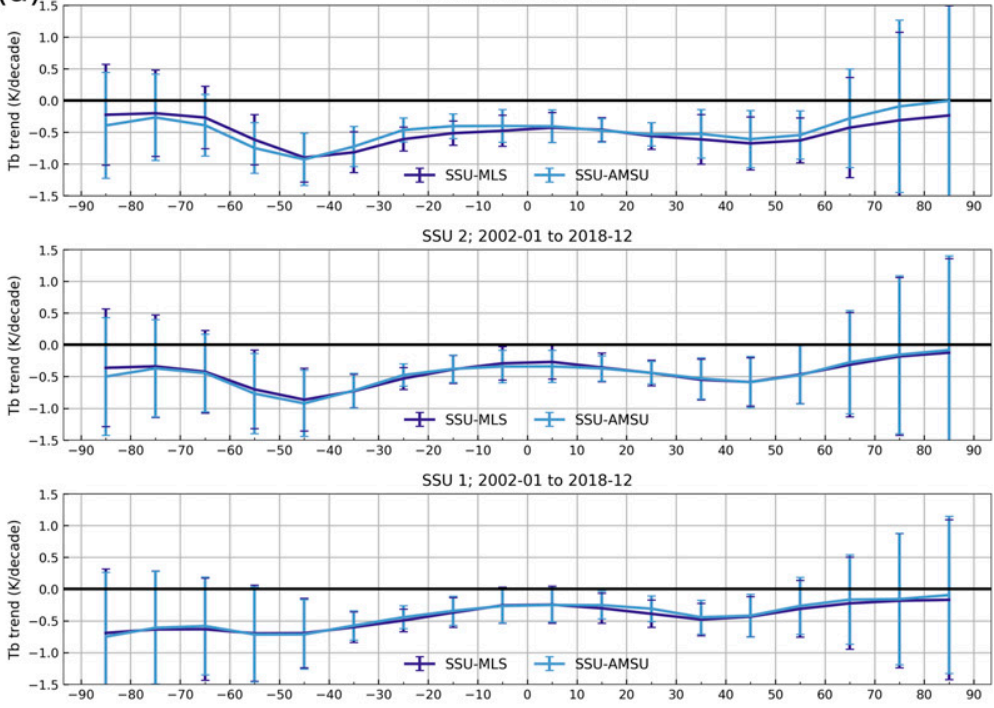

MSU TLS (ch. 4); 2002-01 to 2018-12

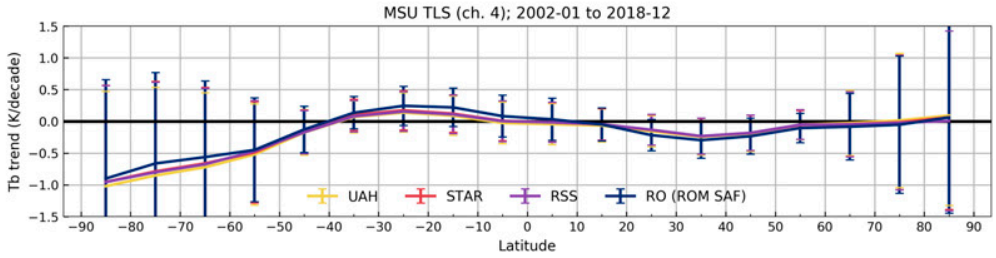

(b)

MSU TTS_corr; 2002-01 to 2018-12

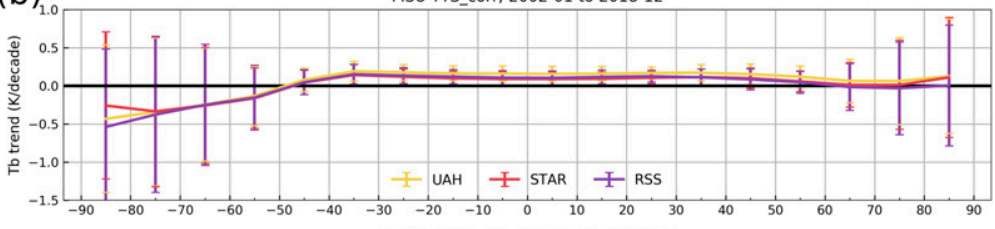

MSU TMT (ch. 2); 2002-01 to 2018-12

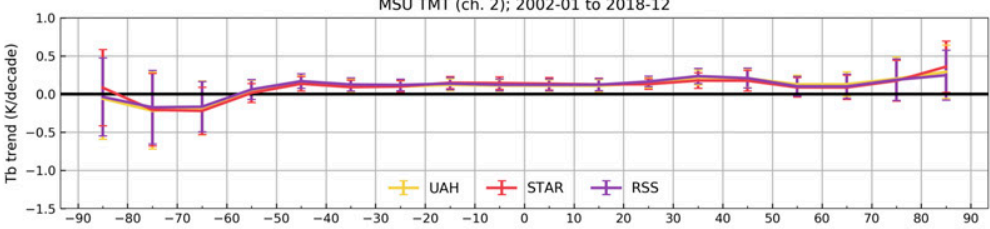

MSU TMT_corr; 2002-01 to 2018-12

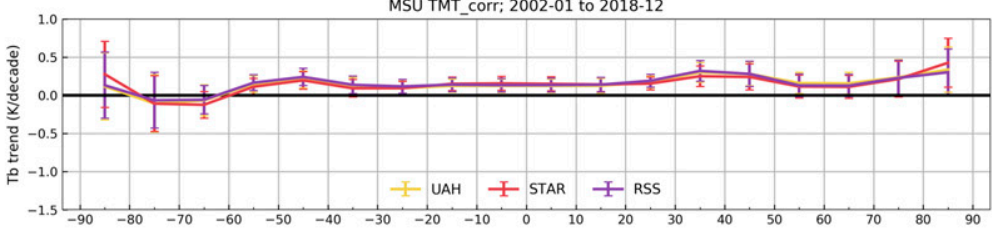

MSU TLT; 2002-01 to 2018-12

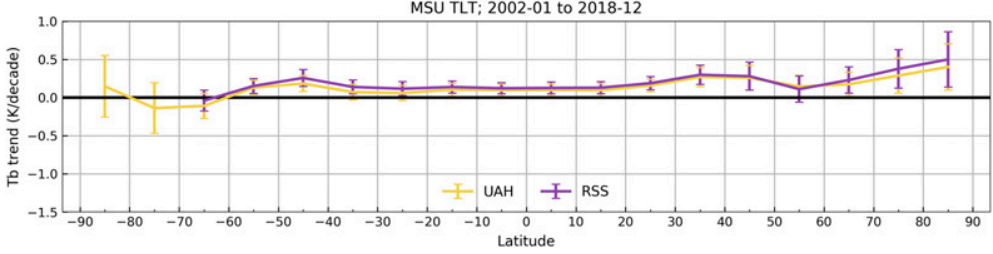

FIG. 7. Latitude structure of trends 2002-18 for (a) stratospheric channels MSU TLS (13-22 km), SSU1 (20-40 km), SSU2 (25-45 km), and SSU3 (35-55 km); and for (b) tropospheric channels MSU TLT, TMTcorr, TMT, and TTScorr, respectively. 
(a)

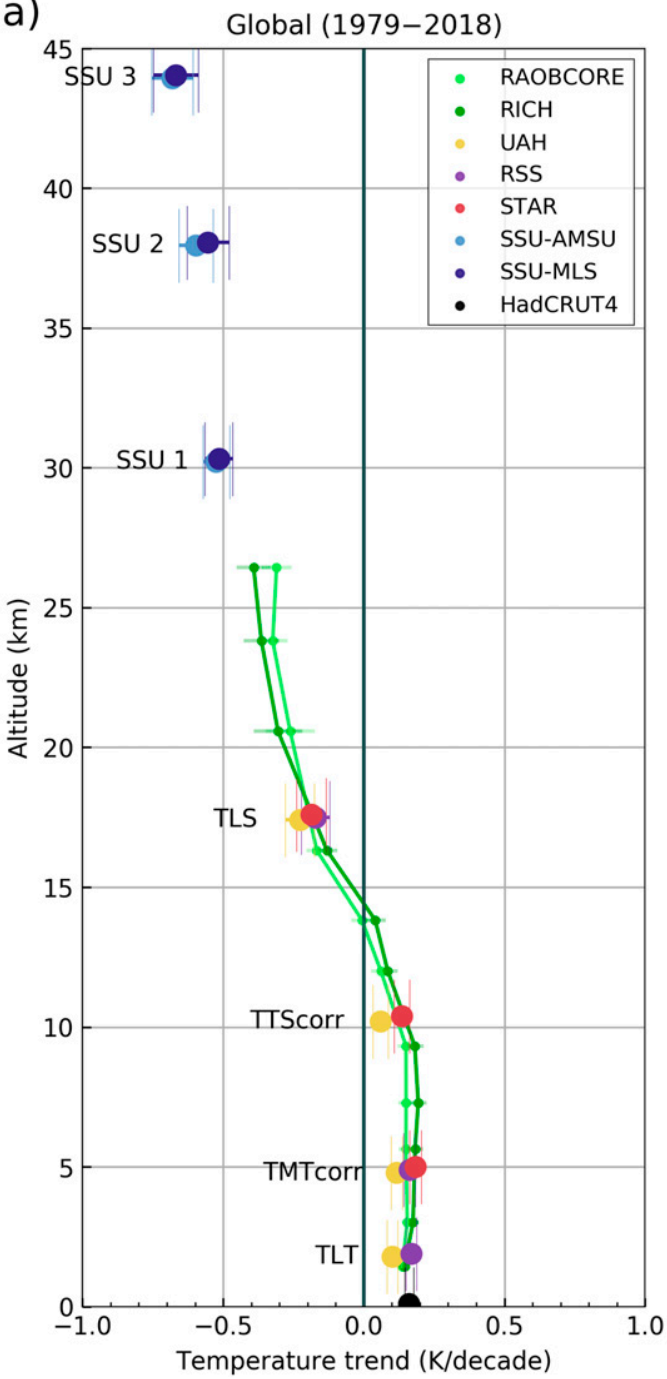

(b)

(b)

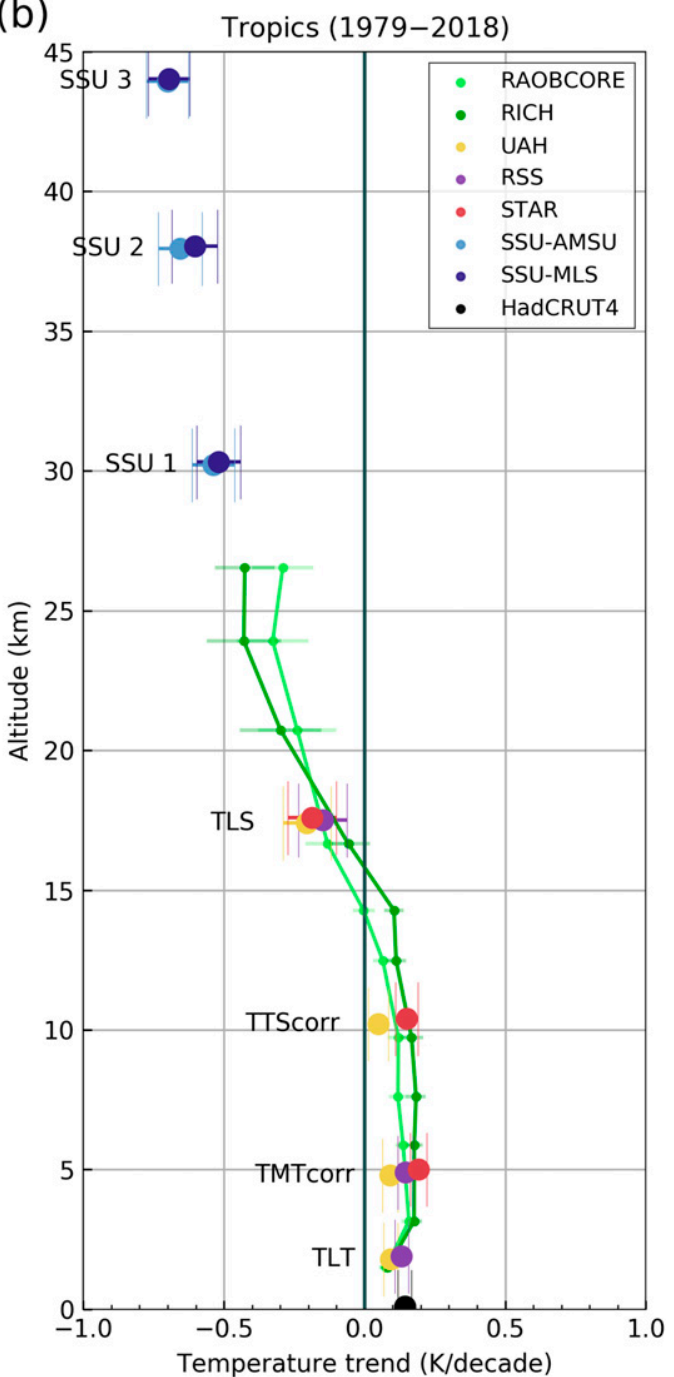

FIG. 8. Upper-air temperature trends 1979-2018 from different observations for (a) near-global averages $\left(70^{\circ} \mathrm{S}-\right.$ $\left.70^{\circ} \mathrm{N}\right)$ and for (b) the tropics $\left(20^{\circ} \mathrm{S}-20^{\circ} \mathrm{N}\right)$. Layer-average temperature trends are shown for MSU-AMSU (RSS, STAR, UAH) and for merged SSU records. Vertically resolved trends are shown for radiosonde records (RICH, RAOBCORE). Surface temperature trends from HadCRUT4 are also indicated. Trends were computed with multiple linear regression. Uncertainty of trends is indicated at the $95 \%$ confidence level.

and TMTcorr trends. In addition, the vertical amplification obtained by comparing the RSS and STAR TMTcorr trends with the surface trends is seen in the tropics (Fig. 8b), which is consistent with results from earlier studies by Fu et al. (2004) and Po-Chedley et al. (2015). UAH TMTcorr trends do not yield amplification of tropical surface warming. The UAH upper-troposphere channel TTScorr shows smaller trends but the STAR TTScorr agrees well with radiosondes, showing impact on trends from different bias correction algorithms in satellite merging.

In the tropical lowermost stratosphere, the cooling rate is about $-0.25 \mathrm{~K}_{\text {decade }}{ }^{-1}$ and increases to about $-0.35 \mathrm{~K}$ decade $^{-1}$, as observed by radiosondes. The cooling increases from $-0.54 \pm 0.08$ to $-0.70 \pm 0.08 \mathrm{~K} \mathrm{decade}^{-1}$ in the mid-upper stratosphere (SSU1 to SSU3) as seen from merged SSU records.

Figure 9 shows the variance explained by the different components of the multiple regression model. Results are for time series of tropical temperature anomalies for 1979-2018, and are for TMTcorr, MSU TLS, and SSU1, SSU2, and SSU3. In the troposphere (TMTcorr), about $45 \%$ of the variance is explained by ENSO. In the lower stratosphere (TLS), stratospheric volcanic aerosols and the QBO explain about $20 \%$ and $15 \%$ of the variance (respectively). In the mid-upper stratosphere (SSU1, SSU2, SSU3), $<10 \%$ variance is explained by the QBO and about 


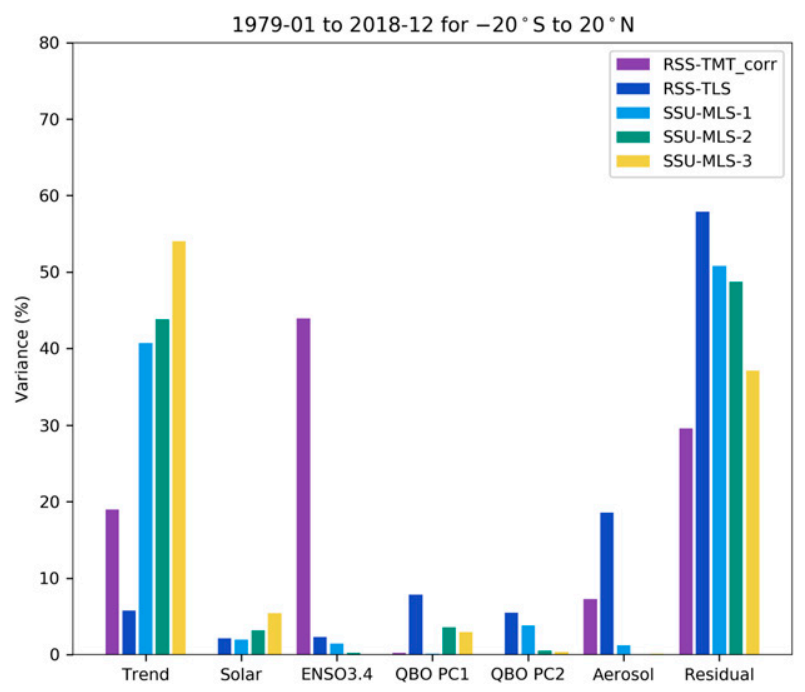

FIG. 9. Percentage of variance explained by the regressors and by the residuals in tropical temperature anomalies 1979-2018 for the tropospheric channel MSU TMTcorr (RSS), and the stratospheric channels MSU TLS (RSS), and SSU1-SSU3 (SSU-MLS). Results are shown for one exemplary record per channel and are consistent for all respective datasets.

$5 \%$ by solar variability. The residuals are relatively large in the stratosphere, in part because of the nonlinear changes in stratospheric ozone over 1979-2018 (Bandoro et al. 2018).

For the shorter period 2002-18, our comparison of upper-air trends (Fig. 10) includes vertically resolved trends from three GNSS RO records (ROM SAF, UCAR/ NOAA, WEGC), the RICH, RAOBCORE, and RSVAIS radiosonde records, and the MSU-AMSU and merged SSU records. In the troposphere up to roughly $10-\mathrm{km}$ altitude, radiosondes show global warming of $0.3 \mathrm{~K} \mathrm{decade}^{-1}$, whereas trends from layer-averaged MSU-AMSU are smaller (Fig. 10a). Trends from radiosondes agree well with trends from RO data in the midtroposphere and in the lower stratosphere. For the latter, a global-mean cooling of about $-0.2 \mathrm{~K} \mathrm{decade}^{-1}$ near $25-\mathrm{km}$ altitude is observed (from $-0.16 \pm 0.11$ to $-0.35 \pm 0.09 \mathrm{~K} \mathrm{decade}{ }^{-1}$ for WEGC and UCAR/ NOAA, ROM SAF). The cooling increases in the midupper stratosphere from $-0.42 \pm 0.06$ to $-0.58 \pm$ $0.08 \mathrm{~K} \mathrm{decade}^{-1}$ (SSU-MLS).

In the tropics (Fig. 10b), tropospheric trends from the different RO records (ROM SAF, UCAR/NOAA, WEGC) are consistent with the RS-VAIS record (within their respective uncertainty estimates) up to $14-\mathrm{km}$ altitude. While gridded radiosonde records (RICH and RAOBCORE) show a warming of about $0.2 \mathrm{~K} \mathrm{decade}^{-1}$ throughout the troposphere (from $0.17 \pm 0.14$ to $0.26 \pm$ $0.14 \mathrm{~K}_{\text {decade }}{ }^{-1}$ ), RO and RS-VAIS show a larger warming in the mid-upper troposphere of about $0.3 \mathrm{~K}$ decade $^{-1}$ (from $0.31 \pm 0.11$ to $0.38 \pm 0.15 \mathrm{~K} \mathrm{decade}^{-1}$ at
9-16 km for ROM SAF). A possible reason for the different trend values in RICH and RAOBCORE is that they only represent conditions over land, while in RSVAIS this sampling bias is corrected. In addition, slightly stronger warming is observed around the tropical tropopause $(\sim 15-18 \mathrm{~km})$ by RO compared to the radiosondes. Observed trends in the tropical stratosphere point to a slight cooling from about -0.1 to $-0.22 \mathrm{~K} \mathrm{decade}^{-1}$ in the lower stratosphere observed in $\mathrm{RO}$ and radiosondes, which increases to $-0.45 \mathrm{~K}$ decade ${ }^{-1}$ in the upper stratosphere in the SSU observations.

The largest trend differences among the different datasets are evident in the tropopause region. In this region we are more confident in trends from $\mathrm{RO}$ observations than in those from radiosonde observations. Inai et al. (2015) reported a pressure bias in Vaisala RS80 sensors that could lead to an artificial trend in temperature. Transitioning from the RS80-dominated time period before 2007 to the RS92-dominated period thereafter may have contributed to weaker TTS trends in the radiosonde record. In addition, radiosonde information is sparser in the tropics and Southern Hemisphere and clustered over Northern Hemisphere continents. While we account for sampling biases in the RS-VAIS record, this is not the case for the gridded RAOBCORE and RICH radiosonde products. Furthermore, the gridded radiosonde records are given on standard pressure levels and do not fully resolve the tropopause region (see Fig. 11). In contrast, the RS-VAIS record provides higher vertical sampling and agrees better with RO. These differences in homogeneity, coverage, and vertical resolution must contribute to the principal trend differences between the vertically resolved data records in the tropopause region.

Slight differences in RO trends at stratospheric altitudes mainly stem from the early CHAMP period before 2006. Due to the larger noise of the CHAMP receiver, the impact of high-altitude initialization propagates further down in the temperature retrieval while later RO missions have improved receivers (Leroy et al. 2018; Shangguan et al. 2019; Steiner et al. 2020). To highlight this sensitivity, we compare trends from 2007 based on a standard linear fit. Figure 11 shows that RO trends from different centers are highly consistent and agree well with the RS-VAIS and the other gridded radiosonde records. We note that the linear changes in Fig. 11 (i.e., upper-tropospheric tropical trends of $\sim 0.8 \mathrm{~K} \mathrm{decade}^{-1}$ ) are not representative of decadal trends, but are intended to illustrate the similar behavior of radiosondes and RO for the short 2007-18 record.

Altitude versus latitude resolved trends for 2002-18 are shown in Fig. 12, revealing global behavior based on the ROM SAF RO and the RICH radiosonde data records. The overall trend patterns are consistent between the satellite-based and ground-based observations, showing 
(a)

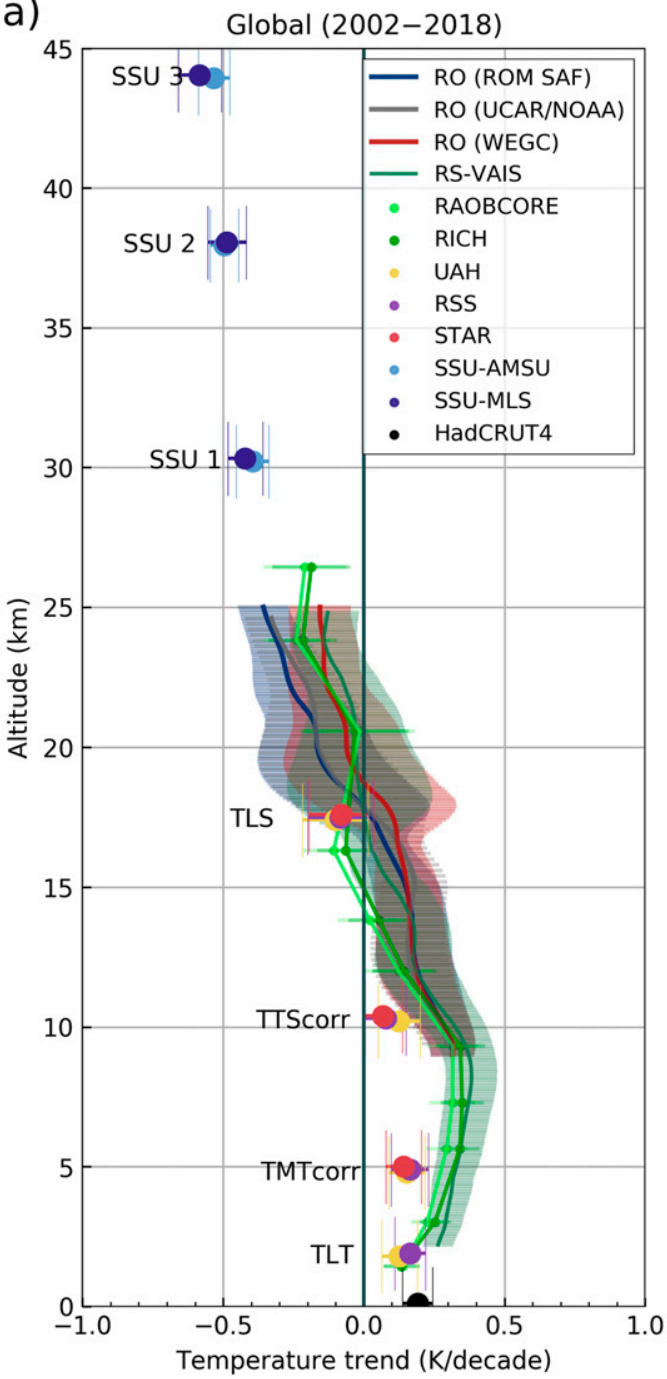

(b)

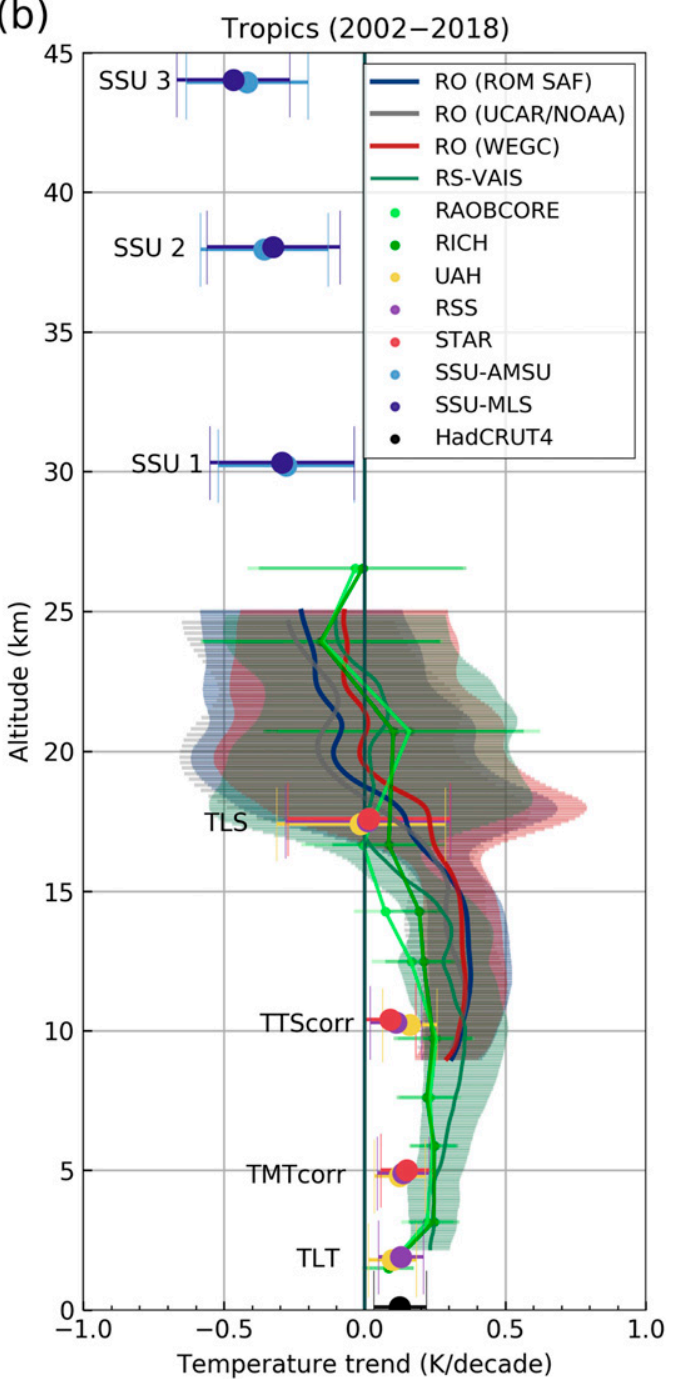

FIG. 10. Upper-air temperature trends $2002-18$ from different observations for (a) near-global averages $\left(70^{\circ} \mathrm{S}-\right.$ $\left.70^{\circ} \mathrm{N}\right)$ and (b) the tropics $\left(20^{\circ} \mathrm{S}-20^{\circ} \mathrm{N}\right)$. Layer-average temperature trends are shown for MSU-AMSU (RSS, STAR, UAH) and for merged SSU records. Vertically resolved trends are shown for radiosonde records (RS-VAIS, RICH, RAOBCORE) and for RO records (ROM SAF, UCAR/NOAA, WEGC). Surface temperature trends from HadCRUT4 are also indicated. Trends were computed with multiple linear regression. The uncertainty of trends is indicated at the $95 \%$ confidence level.

statistically significant warming of the troposphere from about 0.25 to $0.35 \mathrm{~K} \mathrm{decade}^{-1}$. Relatively weak cooling is found throughout much of the stratosphere, apart from a distinct warming of about $0.5 \mathrm{~K}_{\text {decade }}{ }^{-1}$ above the southern tropical tropopause. The latter feature is likely due to variability in the short-term data record. Largest cooling is observed in the southern high-latitude stratosphere but is not significant due to large atmospheric variability.

\section{d. Tropospheric amplification}

In this section we further investigate the observed warming of the tropical upper troposphere and the evidence for tropical amplification of surface warming in the free troposphere. We computed temperature amplification metrics following Santer et al. (2005), calculating ratios of temperature standard deviation and trends at tropospheric vertical levels with respect to HadCRUT4 surface temperatures. We first examine the ratio between the temporal standard deviations of monthly mean tropospheric and surface temperature anomalies as a measure of month-to-month variation. We then inspect the ratio between the multidecadal trends of tropospheric and surface temperature anomalies.

These scaling ratios were computed for radiosondes, $\mathrm{RO}$ records, and MSU data and compared to theoretically 
(a)

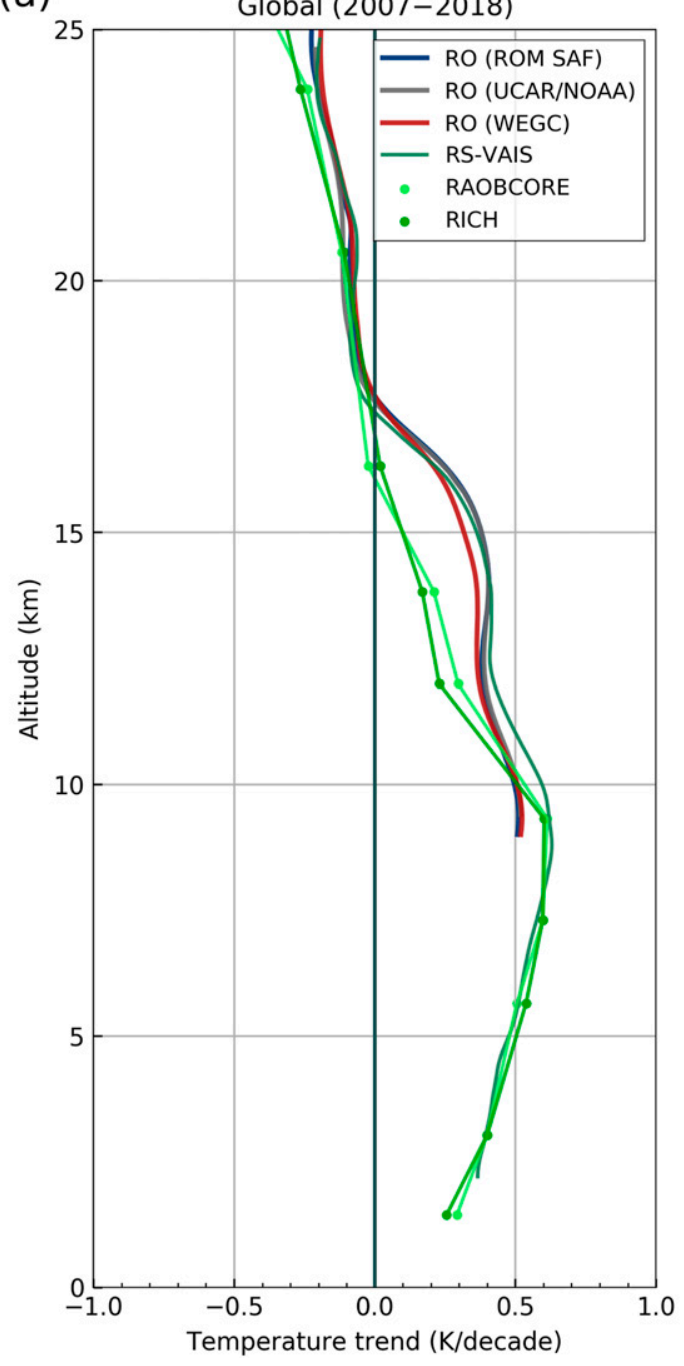

(b)

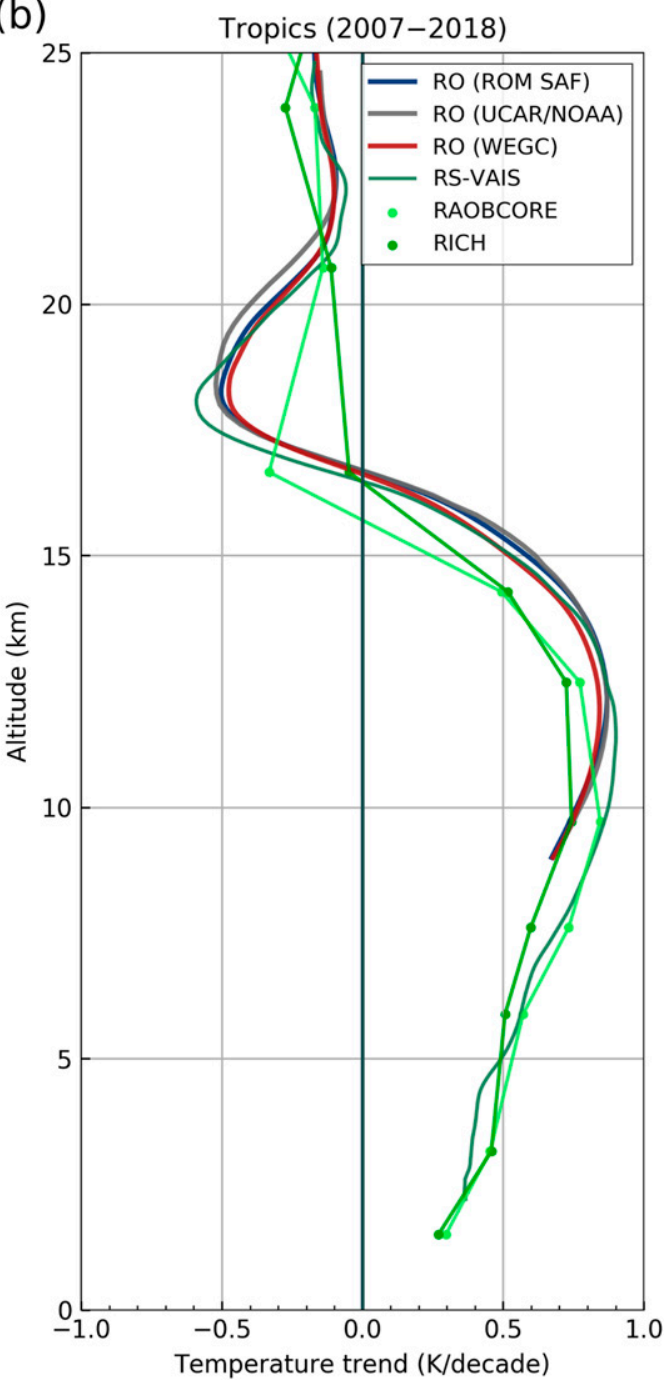

FIG. 11. Upper-air temperature trends 2007-18 based on standard linear fit for comparison of different RO datasets and radiosondes for (a) near-global averages $\left(70^{\circ} \mathrm{S}-70^{\circ} \mathrm{N}\right)$ and $(\mathrm{b})$ the tropics $\left(20^{\circ} \mathrm{S}-20^{\circ} \mathrm{N}\right)$.

expected scaling ratios from moist adiabatic lapse rate theory. The theoretical scaling factors were computed by taking the difference between two moist adiabats with specified tropical-mean surface temperatures of 1-K difference. The difference between these two adiabats at higher altitudes then corresponds to the scaling factor. We estimate a range of plausible surface temperatures in the tropics by averaging over ERA5 $2 \mathrm{~m}$ temperature and humidity. These contain a minimum and maximum estimate as well as mean conditions (approximately 298$300 \mathrm{~K}$ and $73 \%-84 \%$ relative humidity). The scaling factor depends sensitively on the relative humidity at the surface. Assuming saturation at the surface would yield a maximum scaling factor of $\sim 2.8$ in the upper troposphere $(\sim 13 \mathrm{~km})$, whereas with $80 \%$ relative humidity, which is closer to the observed average surface relative humidity in the tropics, the maximum scaling factor is $\sim 2.4$ at slightly lower altitudes. Secondary effects such as phase changes have only a small effect on the amplification (less than 0.1).

Comparison of the standard deviation ratios for the period 1979-2018 (Fig. 13a) shows that for short-term variability, the RICH and RAOBCORE radiosonde records follow the expected moist adiabatic lapse rate up to $8-10 \mathrm{~km}$. Above $10 \mathrm{~km}$, these radiosonde datasets show no further amplification. There is also close agreement between the theoretical expectation of the standard deviation ratios and the MSU TLT and TMTcorr results (with weighting function peaks near 2 and $5 \mathrm{~km}$, respectively, which represent thick vertical layers but are indicated as points). MSU TTScorr shows no further amplification relative to TLT and TMTcorr. 
(a)

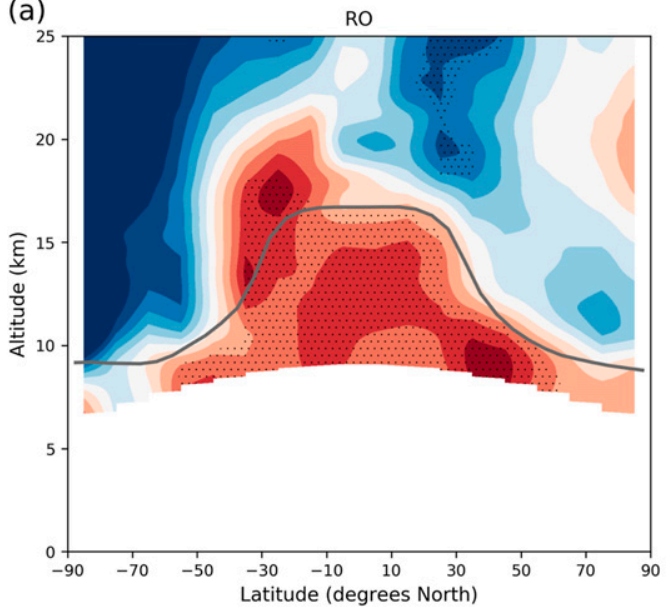

(b)

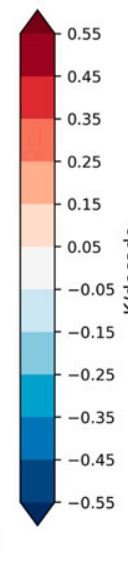

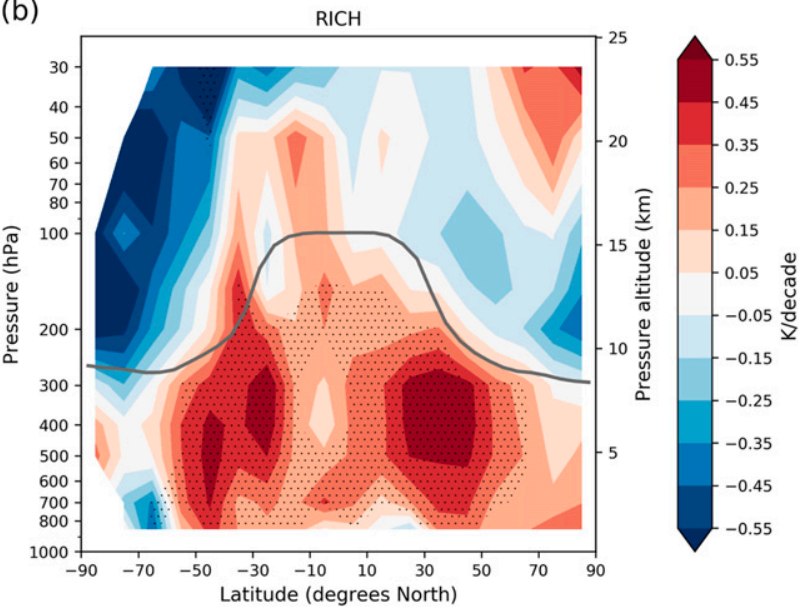

FIG. 12. Altitude vs latitude resolved trends 2002-18 shown for (a) RO (ROM SAF) and (b) radiosondes (RICH). Trends were computed with multiple regression analysis. Trend values that are significant at the $95 \%$ confidence level are indicated with dots.

Now consider scaling ratios for multidecadal tropospheric and surface trends over the period 1979-2018 (Fig. 13b). The scaling ratios of RICH and RAOBCORE do not yield amplification with height and exhibit damping of surface warming (scaling factor $<1$ ) above $10 \mathrm{~km}$. The STAR MSU TMTcorr shows amplification that is consistent with theory, while RSS and UAH MSU data have (respectively) minimal amplification and less warming aloft than at the surface. For TTScorr, surface warming is damped in UAH and has minimal amplification in STAR, showing impact on trends from different bias correction algorithms in satellite merging.

For the RO period 2002-18, we find all radiosonde and RO data records show approximate agreement with the moist adiabatic amplification in terms of short-term variability (Fig. 13c); RO and RS-VAIS exhibit amplification that is larger than the theoretical expectation. For scaling ratios based on trends over 2002-18 (Fig. 13d), each of the datasets show amplification with altitude, but with considerable differences in detail. The RS-VAIS radiosonde and RO trends show strongest amplification (up to a factor of 3.0) in the upper troposphere above $8 \mathrm{~km}$, while the RAOBCORE and RICH data have nearly constant amplification $(\sim 2.0)$ with height above $\sim 3 \mathrm{~km}$. MSU RSS and STAR data show small amplification with STAR TMTcorr being closest to the theoretical lapse rate. TTScorr does not show any amplification, with only slight amplification from UAH TTScorr. This is most likely because the TTScorr weighting function still contains nonnegligible cooling contribution from the lower stratosphere that causes the TTScorr to underestimate the warming trends in the upper troposphere.

When interpreting Fig. 13, one should note that only the best estimate trend curves are shown for clarity.
From Fig. 10, however, one can see that there is substantial uncertainty in trends derived from all datasets. In addition, the scaling ratios depend sensitively on the HadCRUT4 surface trends, and a reduction of the best estimate from 0.14 to $0.11 \mathrm{~K}^{\text {decade }}{ }^{-1}$, which is well within the observational uncertainty range in the tropics (Morice et al. 2012), would enhance the scaling factors of the upper-air datasets by $20 \%$.

Despite this caveat, the datasets in Fig. 13d provide evidence for amplified warming in the tropical upper troposphere over the RO period (2002-18). All observations except MSU TTScorr are able to represent the amplification of month-to-month variability, with $\mathrm{RO}$ and RS-VAIS showing larger upper-troposphere variability. For the multidecadal trends (Figs. 13b,d), the STAR MSU TMTcorr shows an amplification while TTScorr does not. The gridded radiosonde datasets RAOBCORE and RICH show weaker upper-tropospheric amplification for the recent 2002-18 period, and no amplification for 1979-2018. The RO and RS-VAIS trends exhibit the largest increases in amplification with altitude.

\section{Summary and conclusions}

This study provides an overview of updated atmospheric temperature trends estimated from observations and assesses the uncertainties and limitations of currently available data records. Atmospheric observations over the satellite era (1979-2018) have been investigated from satellite-based sensors as well as from groundbased instruments. We constrained our analysis to data records that have been updated until the end of 2018 . We analyzed layer-average temperature from new merged data records of microwave sounders (MSU-AMSU) 
(a)

Tropics (1979-2018)

(b)
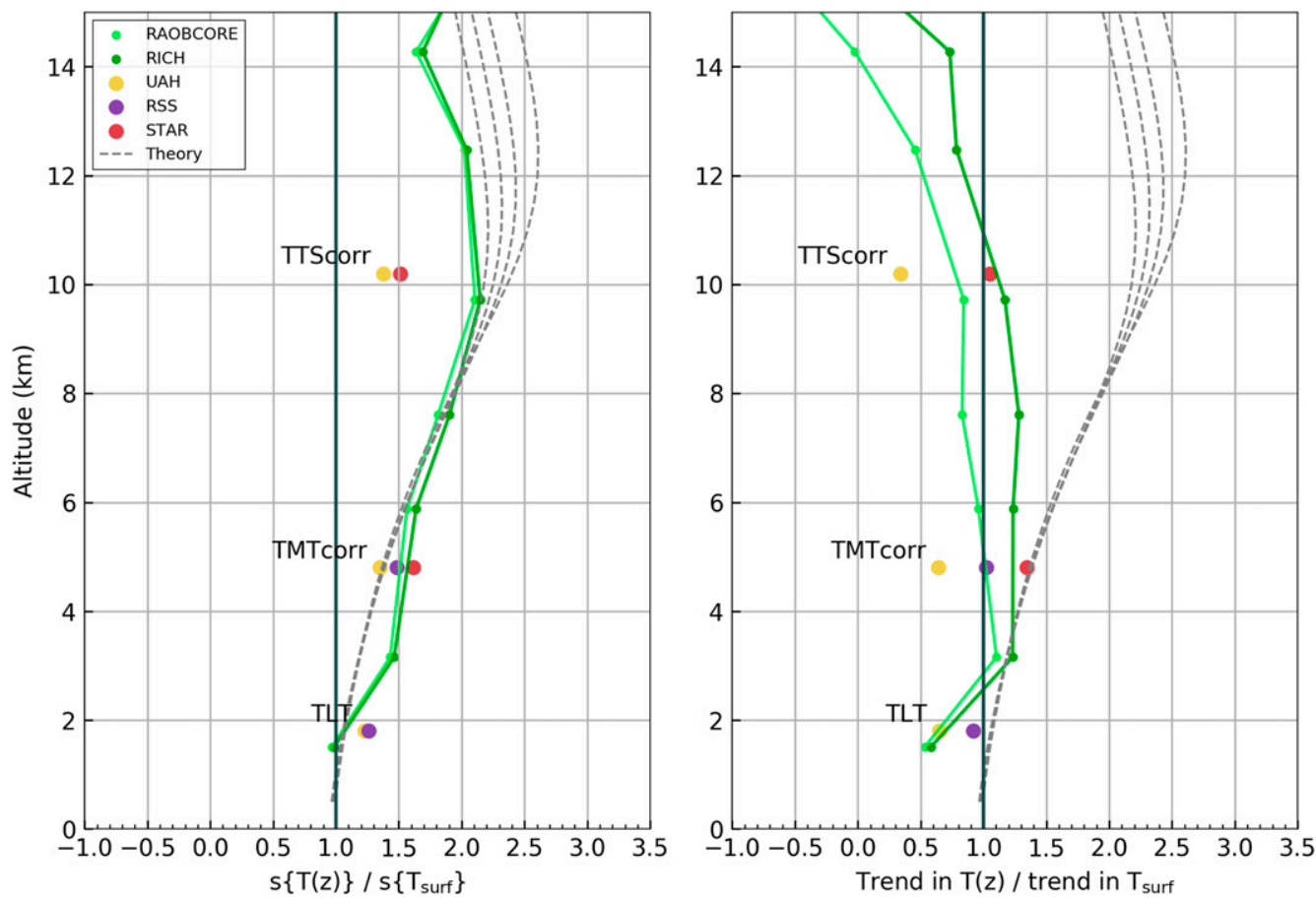

(c)

Tropics (2002-2018)
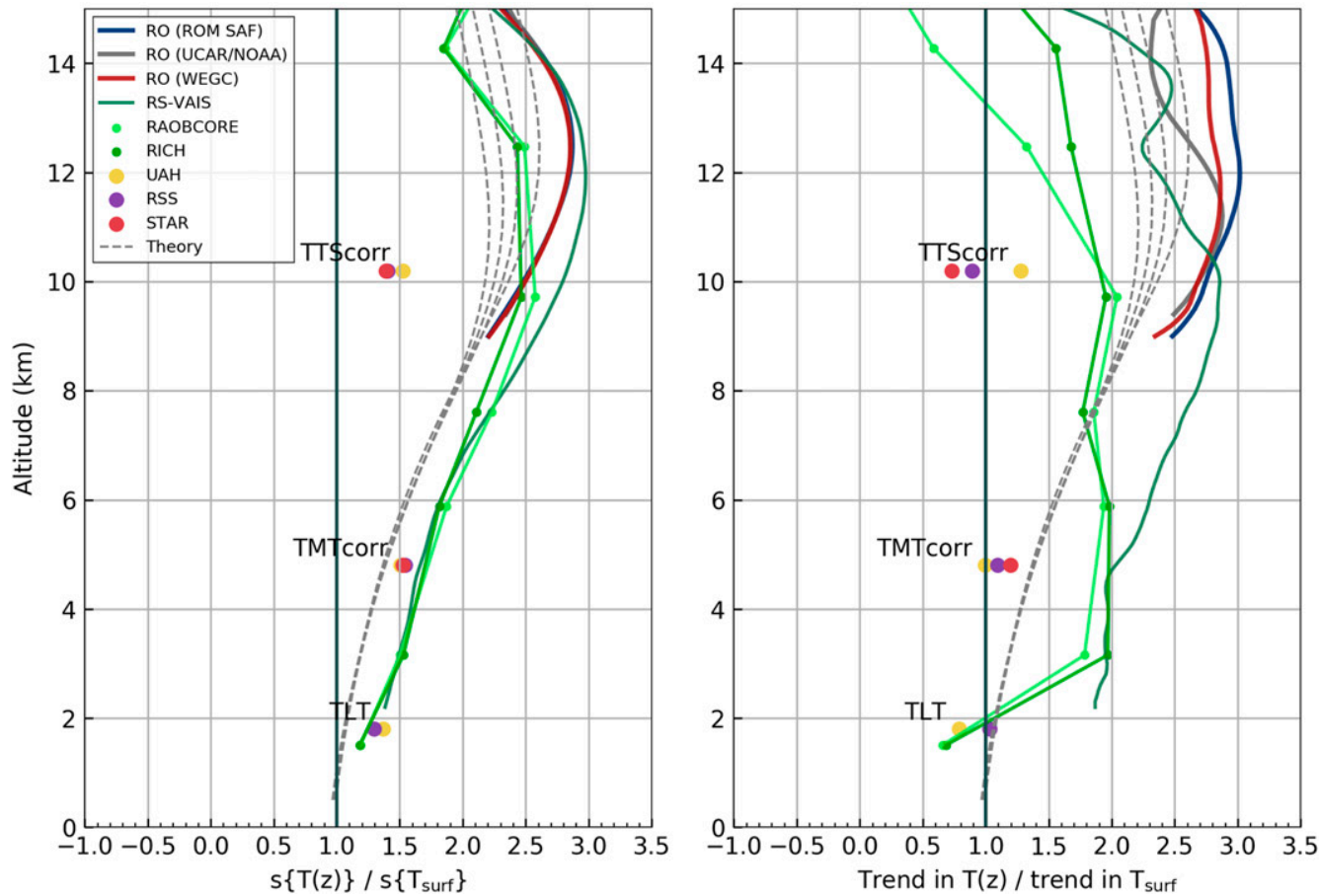

FIG. 13. Atmospheric profiles of temperature scaling ratios for observations and theoretically expected values in the tropics $\left(20^{\circ} \mathrm{S}-20^{\circ} \mathrm{N}\right)$ for the (a),(b) long-term period 1979-2018 and (c),(d) short-term period 2002-18. (left) Ratio between the temporal standard deviations of monthly mean tropospheric and HadCRUT4 surface temperature anomalies as a measure of month-to-month variation. (right) Ratio between the multidecadal trends of tropospheric and surface HadCRUT4 temperature anomalies. 
provided by three data centers and from two merged records of stratospheric sounders (SSU-AMSU and SSUMLS). We compared these datasets to lidar temperatures from four long-term stations and to two gridded homogenized radiosonde records. We also relied on novel GNSS RO from three different centers. The RO data are available since 2001 and have the advantage of long-term stability and high vertical resolution.

Atmospheric trends were estimated for layer-average temperatures and for vertically resolved temperatures based on global-mean and zonal-mean monthly time series. Trends were computed by applying a linear ordinary least squares fit as well as multiple regression analysis. Natural variability terms used in the regression analysis account for the solar cycle, ENSO, stratospheric volcanic eruptions, and the QBO.

Resulting trends show a cooling of the stratosphere with a robust temperature decrease of about $1-3 \mathrm{~K}$ over the last four decades. The rate of cooling evolves over time, particularly in the lower stratosphere. In the first half of the record, cooling is larger and interrupted by volcanically induced stratospheric warming signals. Lower-stratospheric cooling trends are weaker since about 1998. Stronger cooling trends reflect the decline of stratospheric ozone in the early period, while the partial recovery of ozone since about 1998 is consistent with smaller stratospheric cooling trends. In the upper stratosphere, it seems that cooling is enhanced since about 2015.

The latitude structure of trends shows a consistent picture of stratospheric cooling over all latitudes that increases with height. It amounts to about $-0.25 \mathrm{~K}_{\text {decade }}{ }^{-1}$ in the lower stratosphere (TLS) up to from -0.5 to $-0.7 \mathrm{~K} \mathrm{decade}^{-1}$ in the mid-upper stratosphere (SSU1 to SSU3). At northern high latitudes, cooling is up to $1 \mathrm{~K}$ decade $^{-1}$, while it is weaker at southern high latitudes. Model calculations (Randel et al. 2017; Maycock et al. 2018) show large variability in polar stratospheric trends derived from 40-yr samples, especially in the Northern Hemisphere. This indicates that a forced response cannot be easily separated from internal variability and implies that there may be a nonnegligible internally generated component to the larger stratospheric trends in the Northern Hemisphere. The smaller trends over the Antarctic continent are reproduced in the ensemble model simulations of Randel et al. (2017), suggesting a link to systematic circulation changes in response to ozone depletion during the Austral summer. In the lower stratosphere, the latitudinal trend structure shows cooling over all latitudes and a near-zero trend at northern high latitudes. Changes in ozone and the BDC are important factors in the latitudinal pattern of the lower-stratospheric cooling trend, while greenhouse gases and ozone changes dominate above.
In the troposphere, the observed warming over the last four decades is roughly $0.6-0.8 \mathrm{~K}$, with prominent variability associated with ENSO. Tropospheric trends show significant warming over all latitudes, except at southern high latitudes. Largest warming trends occurred at northern high latitudes. Overall, the different types of atmospheric record show reasonable agreement.

Vertically resolved trends for the period 2002-18 based on radiosonde data and novel GNSS RO records have consistent warming trends in the tropical troposphere up to $14 \mathrm{~km}$. While gridded radiosonde records $(\mathrm{RICH}$ and RAOBCORE) warm by about $0.2 \mathrm{~K} \mathrm{decade}^{-1}$ throughout the troposphere, GNSS RO and Vaisala sonde-based radiosondes (RS-VAIS) yield larger warming of about $0.3 \mathrm{~K} \mathrm{decade}^{-1}$. In the lower tropical stratosphere, slight cooling is observed in the last two decades.

Over this shorter RO period, warming in the troposphere tends to be uniform over all latitudes except for southern high latitudes. Importantly, the RO period provides evidence for amplified warming of surface temperature trends in the tropical upper troposphere. This evidence is in high vertical resolution RO data and radiosonde records, both of which yield amplification behavior that is in approximate agreement with moist adiabatic lapse rate theory.

For trends over the longer period 1979-2018 the results are more ambiguous. While there is no evidence for tropospheric amplification in the gridded radiosonde records at standard pressure levels, amplification in the STAR MSU TMTcorr data is consistent with theory. For the upper-tropospheric MSU TTScorr, however, no amplification is currently observed over the full satellite era.

Differences in trends in the different types of measurement platform are generally largest in the tropopause region $(13-18 \mathrm{~km})$, which may be due to changes in the radiosonde instrumentation and sampling. RO observations are of highest quality in the upper-tropospherelower-stratosphere region. We are therefore more confident in trends in this region estimated from $\mathrm{RO}$ observations than in trends inferred from radiosonde observations. Further research is required to better explain remaining differences between different measurement types and between the estimates of one measurement type obtained by different groups. Although at stratospheric altitudes there are slight differences in RO trends over 2002-18 due to limitations in the early CHAMP mission, we found RO trends after 2006 to be highly consistent across different research groups.

There is also consistency between the overall latitudealtitude trend patterns from GNSS RO and radiosondes. Significant warming of the troposphere is clearly revealed by both measurement platforms, with values of approximately $0.25-0.35 \mathrm{~K} \mathrm{decade}^{-1}$ and distinct warming of about $0.5 \mathrm{~K} \mathrm{decade}^{-1}$ above the southern tropical tropopause. 
In conclusion, we find overall consistency in observed trends over 1979-2018 obtained from the latest observational records for satellite-based layer-average temperatures and vertically resolved radiosonde records. Novel records from GNSS RO, available for 2002-18, show consistent trends with radiosondes over this shorter period of record.

Long-term climate records are essential for gaining fundamental understanding of climate variability and climate trends, for identification of externally forced climate change, and for estimating the sensitivity of Earth's climate to the changing composition of trace gases and aerosols. To sustain long-term climate data records of key climate variables, it will be essential to maintain reliable long-term monitoring of Earth's climate with such platforms as the Global Climate Observing System (GCOS).

Acknowledgments. The authors express their gratitude to SPARC for supporting the ATC activity in their work described in this article. These activities have been undertaken under the guidance and sponsorship of the World Climate Research Programme. We acknowledge the groups at NOAA/STAR, RSS, and $\mathrm{UAH}$ who have produced and made available the satellite temperature data sets used in this study. We acknowledge UCAR/CDAAC (Boulder, CO, United States) for providing access to RO phase, orbit data, and temperature data, as well as to ECMWF (Reading, United Kingdom) for giving access to analysis and forecast data. We also thank the WEGC EOPAC team for providing the OPSv5.6 RO data, and the ROM SAF team for providing the ROM SAF CDR v1. The lidar data used in this publication were obtained from the Norwegian Institute for Air Research (NILU) as part of the Network for the Detection of Atmospheric Composition Change (NDACC) and are publicly available (see http://www.ndacc.org). The GloSSAC data set was obtained from the NASA Langley Research Center Atmospheric Sciences Data Center. We acknowledge FU Berlin (Berlin, Germany) for providing Singapore wind data. For C.-Z. Zou, the views, opinions, and findings contained in this report are those of the authors and should not be construed as an official NOAA or U.S. Government position, policy, or decision. Part of this research was carried out at the Jet Propulsion Laboratory, California Institute of Technology, under a contract with the National Aeronautics and Space Administration (80NM0018D0004). Q. Fu was supported by the NASA grant $80 \mathrm{NSSC} 18 \mathrm{~K} 1031$. L. Haimberger was supported by FWF grant P28818-N29 and EU 7FP grant 607029 (ERACLIM2). A.K. Steiner and F. Ladstädter were funded by the Austrian Science Fund (FWF) under research grant P27724-NBL (VERTICLIM), and by the FFG-ALR project ATROMSAF1(ASAP-13 859771).

\section{APPENDIX}

\section{Acronym List}

ACE-FTS

AMSU

AMSU-A

ATC

BDC

CCMI

CDR

CHAMP

ECV

ECMWF

ENSO

ERA-Interim

ERA5.1

GCOS

GloSSAC

GNSS

GOMOS

GPS

GRUAN

HadAT

$\mathrm{HOH}$

IGRA

IPCC

IUK

JPL

LATMOS

Lidar

MetOp

MIPAS
Atmospheric Chemistry ExperimentFourier Transform Spectrometer

Advanced Microwave Sounding Unit (1998 to present)

Advanced Microwave Sounding Unit-A (unit A for temperature sounding)

Atmospheric Temperature Changes and

Their Drivers (WCRP/SPARC activity)

Brewer-Dobson circulation

Chemistry Climate Model Initiative

Climate data record

Challenging Minisatellite Payload

Essential climate variable

European Centre for Medium-Range Weather Forecasts

El Niño-Southern Oscillation

ECMWF interim reanalysis

Fifth Global Reanalysis of ECMWF, version 5.1

Global Climate Observing System

Global Space-Based Stratospheric Aerosol Climatology

Global Navigation Satellite System

Global Ozone Monitoring by Occultation of Stars

Global Positioning System

GCOS Reference Upper Air Network

Hadley Centre Atmospheric Temperature radiosonde data (Met Office, United Kingdom)

Hohenpeissenberg Observatory

Integrated Global Radiosonde Archive (NOAA)

Intergovernmental Panel on Climate Change

Iterative universal kriging radiosonde record (University of New South Wales, Sydney, Australia)

Jet Propulsion Laboratory (Pasadena, California)

Laboratoire Atmosphères, Milieux, Observations Spatiales (Université Paris-Saclay, Paris, France)

Light detection and ranging

Meteorological Operational satellite (of EUMETSAT Polar System)

Michelson Interferometer for Passive Atmospheric Sounding 


$\begin{array}{lll}\text { MLO } & \text { Mauna Loa Observatory } & \text { UCAR } \\ \text { MLS } & \text { Microwave Limb Sounder } & \\ \text { MSU } & \text { Microwave Sounding Unit (1979 to 2005) } & \text { UKMO } \\ \text { NASA } & \begin{array}{l}\text { National Aeronautics and Space } \\ \text { Administration }\end{array} & \text { UNEP } \\ & \text { WCRP } \\ \text { NDACC } & \begin{array}{c}\text { Network for the Detection of Atmospheric } \\ \text { Composition Change }\end{array} & \text { WEGC } \\ & \begin{array}{c}\text { National Environmental Satellite, } \\ \text { NESDIS }\end{array} & \text { WMO } \\ & \begin{array}{c}\text { Data, and Information Service } \\ \text { NOAA }\end{array} & \begin{array}{c}\text { National Oceanic and Atmospheric } \\ \text { Administration }\end{array} \\ & \text { NOAA Polar Operational Environmental } & \end{array}$

NOAA-9 NOAA Polar Operational Environmental Satellite 9

$\begin{array}{ll}\text { OHP } & \text { Observatoire de Haute Provence } \\ \text { PC } & \text { Principal component } \\ \text { QBO } & \text { Quasi-biennial oscillation } \\ \text { RAOBCORE } & \text { Radiosonde Observation using Reanalysis } \\ \text { RATPAC } & \begin{array}{c}\text { Radiosonde Atmospheric Temperature } \\ \text { Products for Assessing Climate } \\ \end{array} \\ & \text { (NOAA) }\end{array}$

RICH Radiosonde Innovation Composite Homogenization

RO Radio occultation

ROM SAF Radio Occultation Meteorology Satellite Application Facility (DMI, Denmark)

RSS

SABER

SI

SPARC

SST

SSU

SSU1/2/3

STAR

TIROS-N

TLS

TLT

TMF

TMT

TUT or TTS

$\mathrm{UAH}$
Remote Sensing Systems (Santa Rosa, California)

Sounding of the Atmosphere Using Broadband Emission Radiometry

Système International d'Unités (International System of Units)

Stratospheric-Tropospheric Processes and Their Role in Climate (WCRP core project)

Sea surface temperature

Stratospheric Sounding Unit

SSU channel 1/2/3

Center for Satellite Applications and Research (NOAA/NESDIS)

Television and Infrared Observation Satellite-N (NOAA)

Temperature lower stratosphere (MSU channel 4/AMSU-A channel 9)

Temperature lower troposphere (MSU 2/AMSU-A channel 5 extrapolated)

Table Mountain Facility

Temperature middle troposphere (MSU channel 2/AMSU-A channel 5)

Temperature upper troposphere (MSU channel 3/AMSU-A channel 7)

University of Alabama (Huntsville, Alabama)
University Corporation for Atmospheric Research (Boulder, Colorado)

Met Office

United Nations Environment Programme World Climate Research Programme

Wegener Center for Climate and Global Change (University of Graz, Austria)

World Meteorological Organization

\section{REFERENCES}

Angerer, B., F. Ladstädter, B. Scherllin-Pirscher, M. Schwärz, A. K. Steiner, U. Foelsche, and G. Kirchengast, 2017: Quality aspects of the Wegener Center multi-satellite GPS radio occultation record OPSv5.6. Atmos. Meas. Tech., 10, 4845-4863, https://doi.org/10.5194/amt-10-4845-2017.

Anthes, R. A., 2011: Exploring Earth's atmosphere with radio occultation: Contributions to weather, climate and space weather. Atmos. Meas. Tech., 4, 1077-1103, https://doi.org/ 10.5194/amt-4-1077-2011.

Baldwin, M. P., and Coauthors, 2001: The quasi-biennial oscillation. Rev. Geophys., 39, 179-229, https://doi.org/10.1029/1999RG000073.

Bandoro, J., S. Solomon, B. D. Santer, D. E. Kinnison, and M. J. Mills, 2018: Detectability of the impacts of ozone-depleting substances and greenhouse gases upon stratospheric ozone accounting for nonlinearities in historical forcings. Atmos. Chem. Phys., 18, 143-166, https://doi.org/10.5194/acp-18-143-2018.

Bernath, P. F., 2017: The Atmospheric Chemistry Experiment (ACE). J. Quant. Spectrosc. Radiat. Transfer, 186, 3-16, https://doi.org/10.1016/j.jqsrt.2016.04.006.

Bodeker, G. E., and Coauthors, 2016: Reference upper-air observations for climate: From concept to reality. Bull. Amer. Meteor. Soc., 97, 123-135, https://doi.org/10.1175/BAMS-D14-00072.1.

Chen, X., and X. Zou, 2014: Postlaunch calibration and bias characterization of AMSU-A upper air sounding channels using GPS RO data. J. Geophys. Res. Atmos., 119, 3924-3941, https://doi.org/10.1002/2013JD021037.

Christy, J. R., R. W. Spencer, and W. D. Braswell, 2000: MSU tropospheric temperatures: Dataset construction and radiosonde comparisons. J. Atmos. Oceanic Technol., 17, 1153-1170, https://doi.org/ 10.1175/1520-0426(2000)017<1153:MTTDCA > 2.0.CO;2.

$\longrightarrow,-$ W. B. Norris, W. D. Braswell, and D. E. Parker, 2003: Error estimates of version 5.0 of MSU-AMSU bulk atmospheric temperatures. J. Atmos. Oceanic Technol., 20, 613-629, https://doi.org/ 10.1175/1520-0426(2003)20<613:EEOVOM>2.0.CO;2.

W. B. Norris, R. W. Spencer, and J. J. Hnilo, 2007: Tropospheric temperature change since 1979 from tropical radiosonde and satellite measurements. J. Geophys. Res., 112, D06102, https://doi.org/10.1029/2005JD006881.

CPC, 2019: Monthly ERSSTv5 (1981-2010 base period) Nino3.4 SST anomaly index. NCEP, accessed 1 November 2019, https:// www.cpc.ncep.noaa.gov/data/indices.

EOPAC Team, 2019: Wegener Center GNSS radio occultation record OPS 5.6 2001-2018. WEGC, accessed 1 November 2019, https://doi.org/10.25364/WEGC/OPS5.6:2019.1.

Fischer, H., and Coauthors, 2008: MIPAS: An instrument for atmospheric and climate research. Atmos. Chem. Phys., 8, 21512188, https://doi.org/10.5194/acp-8-2151-2008. 
Foelsche, U., M. Borsche, A. K. Steiner, A. Gobiet, B. Pirscher, G. Kirchengast, J. Wickert, and T. Schmidt, 2008: Observing upper troposphere-lower stratosphere climate with radio occultation data from the CHAMP satellite. Climate Dyn., 31, 49-65, https://doi.org/10.1007/s00382-007-0337-7.

_ B. Scherllin-Pirscher, F. Ladstädter, A. K. Steiner, and G. Kirchengast, 2011: Refractivity and temperature climate records from multiple radio occultation satellites consistent within 0.05\%. Atmos. Meas. Tech., 4, 2007-2018, https:// doi.org/10.5194/amt-4-2007-2011.

Free, M., and D. J. Seidel, 2009: Observed El Niño-Southern Oscillation temperature signal in the stratosphere. J. Geophys. Res., 114, D23108, https://doi.org/10.1029/2009JD012420.

_ , J. K. Angell, I. Durre, J. Lanzante, T. C. Peterson, and D. J. Seidel, 2004: Using first differences to reduce inhomogeneity in radiosonde temperature datasets. J. Climate, 17, 4171-4179, https://doi.org/10.1175/JCLI3198.1.

Fu, Q., and C. M. Johanson, 2005: Satellite-derived vertical dependence of tropical tropospheric temperature trends. Geophys. Res. Lett., 32, L10703, https://doi.org/10.1029/ 2004GL022266.

_ , and P. Lin, 2011: Poleward shift of subtropical jets inferred from satellite-observed lower-stratospheric temperatures. J. Climate, 24, 5597-5603, https://doi.org/10.1175/JCLI-D-11-00027.1.

—, C. M. Johanson, S. G. Warren, and D. J. Seidel, 2004: Contribution of stratospheric cooling to satellite-inferred tropospheric temperature trends. Nature, 429, 55-58, https:// doi.org/10.1038/nature02524.

—_ _ _ J. M. Wallace, and T. Reichler, 2006: Enhanced midlatitude tropospheric warming in satellite measurements. Science, 312, 1179, https://doi.org/10.1126/science.1125566.

—, S. Manabe, and C. M. Johanson, 2011: On the warming in the tropical upper troposphere: Models versus observations. Geophys. Res. Lett., 38, L15704, https://doi.org/10.1029/ 2011 GL048101.

_ P. Lin, S. Solomon, and D. L. Hartmann, 2015: Observational evidence of strengthening of the Brewer-Dobson circulation since 1980. J. Geophys. Res. Atmos., 120, 10214-10228, https://doi.org/10.1002/2015JD023657.

— , S. Solomon, H. A. Pahlavan, and P. Lin, 2019: Observed changes in Brewer-Dobson circulation for 1980-2018. Environ. Res. Lett., 14, 114026, https://doi.org/10.1088/1748-9326/ab4de7.

FU Berlin, 2019: The Quasi-Biennial-Oscillation (QBO) Data Series [data file: qbo.dat]. Freie Universität, accessed 1 November 2019, https://www.geo.fu-berlin.de/en/met/ag/strat/ produkte/qbo/index.html.

Fujiwara, M., and Coauthors, 2017: Introduction to the SPARC Reanalysis Intercomparison Project (S-RIP) and overview of the reanalysis systems. Atmos. Chem. Phys., 17, 1417-1452, https://doi.org/10.5194/acp-17-1417-2017.

Funatsu, B. M., C. Claud, P. Keckhut, W. Steinbrecht, and A. Hauchecorne, 2011: Investigations of stratospheric temperature regional variability with lidar and Advanced Microwave Sounding Unit. J. Geophys. Res., 116, D08106, https://doi.org/10.1029/ 2010JD014974.

,,,--- A. Hauchecorne, and T. Leblanc, 2016: Regional and seasonal stratospheric temperature trends in the last decade (2002-2014) from AMSU observations. J. Geophys. Res. Atmos., 121, 8172-8185, https://doi.org/10.1002/2015JD024305.

GCOS, 2011: Systematic observation requirements for satellite-based data products for climate. World Meteorological Organization, accessed 3 September 2019, https://library.wmo.int/doc_num.php? explnum_id=3710.
_ 2016: The global observing system for climate: Implementation needs. World Meteorological Organization, accessed 3 September 2019, https://library.wmo.int/doc_num.php?explnum_id=3417.

Gleisner, H., K. B. Lauritsen, J. K. Nielsen, and S. Syndergaard, 2020: Evaluation of the 15-year ROM SAF monthly mean GPS radio occultation climate data record. Atmos. Meas. Tech., 13, 3081-3098, https://doi.org/10.5194/amt-13-3081-2020.

Gorbunov, M. E., H.-H. Benzon, A. S. Jensen, M. S. Lohmann, and A. S. Nielsen, 2004: Comparative analysis of radio occultation processing approaches based on Fourier integral operators. Radio Sci., 39, RS6004, https://doi.org/10.1029/2003RS002916.

HadCRUT4, 2020: Surface temperature record of the Met Office Hadley Centre and the Climatic Research Unit at the University of East Anglia. Met Office Hadley Centre, accessed 20 March 2020, https://crudata.uea.ac.uk/cru/data/temperature.

Haimberger, L., 2019: Homogenized radiosonde records RAOBCORE/ RICH version 1.5.1. University of Vienna, accessed 1 November 2019, img.univie.ac.at/forschung/meteorologie/produkte/raobcorerich.

_ C. Tavolato, and S. Sperka, 2008: Toward elimination of the warm bias in historic radiosonde temperature records-Some new results from a comprehensive intercomparison of upperair data. J. Climate, 21, 4587-4606, https://doi.org/10.1175/ 2008JCLI1929.1.

,-- , and - , 2012: Homogenization of the global radiosonde temperature dataset through combined comparison with reanalysis background series and neighboring stations. J. Climate, 25, 81088131, https://doi.org/10.1175/JCLI-D-11-00668.1.

Harris, N. R. P., and Coauthors, 2015: Past changes in the vertical distribution of ozone-Part 3: Analysis and interpretation of trends. Atmos. Chem. Phys., 15, 9965-9982, https://doi.org/ 10.5194/acp-15-9965-2015.

Hartmann, D. L., and Coauthors, 2013: Observations: Atmosphere and surface. Climate Change 2013: The Physical Science Basis, T. F. Stocker et al., Eds., Cambridge University Press, 159-254.

Hauchecorne, A., and M.-L. Chanin, 1980: Density and temperature profiles obtained by lidar between 35 and $70 \mathrm{~km}$. Geophys. Res. Lett., 7, 565-568, https://doi.org/10.1029/GL007i008p00565.

_ and P. Keckhut, 2019: Vertical profiles of temperature from NDACC/OHP Rayleigh Lidar Level 2. LATMOS, accessed 1 November 2019, http://doi.latmos.ipsl.fr/DOI_NDACC_OHP_ LTA.L2.v1.

_- and Coauthors, 2019: A new MesosphEO data set of temperature profiles from 35 to $85 \mathrm{~km}$ using Rayleigh scattering at limb from GOMOS/ENVISAT daytime observations. Atmos. Meas. Tech., 12, 749-761, https://doi.org/10.5194/amt-12-749-2019.

Hersbach, H., and Coauthors, 2020: The ERA5 global reanalysis. Quart. J. Roy. Meteor. Soc., 146, 1999-2049, https://doi.org/ 10.1002/qj.3803.

Ho, S.-P., Y.-H. Kuo, W. S. Schreiner, and X. Zhou, 2010: Using SItraceable global positioning system radio occultation measurements for climate monitoring [in "State of the Climate in 2009']. Bull. Amer. Meteor. Sci., 91 (7), S36-S37, https:// doi.org/10.1175/BAMS-91-7-StateoftheClimate.

— tion data for climate monitoring: Profile-to-profile intercomparison of CHAMP climate records 2002 to 2008 from six data centers. J. Geophys. Res., 117, D18111, https://doi.org/ 10.1029/2012JD017665.

— L L. Peng, and H. Vömel, 2017: Characterization of the longterm radiosonde temperature biases in the upper troposphere and lower stratosphere using COSMIC and Metop-A/GRAS data from 2006 to 2014. Atmos. Chem. Phys., 17, 4493-4511, https://doi.org/10.5194/acp-17-4493-2017. 
- , and Coauthors, 2020: The COSMIC/FORMOSAT-3 radio occultation mission after 12 years: Accomplishments, remaining challenges, and potential impacts of COSMIC-2. Bull. Amer. Meteor. Soc., 101, E1107-E1136, https://doi.org/10.1175/BAMS-D18-0290.1.

Huang, B., and Coauthors, 2017: Extended Reconstructed Sea Surface Temperature, version 5 (ERSSTv5): Upgrades, validations, and intercomparisons. J. Climate, 30, 8179-8205, https://doi.org/10.1175/JCLI-D-16-0836.1.

Inai, Y., M. Shiotani, M. Fujiwara, F. Hasebe, and H. Vömel, 2015: Altitude misestimation caused by the Vaisala RS80 pressure bias and its impact on meteorological profiles. Atmos. Meas. Tech., 8, 4043-4054, https://doi.org/10.5194/amt-8-4043-2015.

Johanson, C. M., and Q. Fu, 2006: Robustness of tropospheric temperature trends from MSU channels 2 and 4. J. Climate, 19, 4234-4242, https://doi.org/10.1175/JCLI3866.1.

Kamae, Y., H. Shiogama, M. Watanabe, M. Ishii, H. Ueda, and M. Kimoto, 2015: Recent slowdown of tropical upper tropospheric warming associated with Pacific climate variability. Geophys. Res. Lett., 42, 2995-3003, https://doi.org/10.1002/ 2015 GL063608.

Karl, T. R., S. J. Hassol, C. D. Miller, and W. L. Murray, Eds., 2006: Temperature trends in the lower atmosphere: Steps for understanding and reconciling differences. Climate Change Science Program and the Subcommittee on Global Change Research, 178 pp.

Karpechko, A. Y., A. C. Maycock, M. Abalos, H. Akiyoshi, J. M. Arblaster, C. I. Garfinkel, K. H. Rosenlof, and M. Sigmond, 2019: Stratospheric ozone and climate. Scientific Assessment of Ozone Depletion: 2018. Global Ozone Research Monitoring Project 58, WMO, accessed 21 December 2019, http://eprints.whiterose.ac.uk/ 142289.

Keckhut, P., A. Hauchecorne, and M. L. Chanin, 1993: A critical review of the database acquired for the long-term surveillance of the middle atmosphere by the French Rayleigh lidars. J. Atmos. Oceanic Technol., 10, 850-867, https://doi.org/ 10.1175/1520-0426(1993)010<0850:ACROTD >2.0.CO;2. , and Coauthors, 2004: Review of ozone and temperature lidar validations performed within the framework of the network for the detection of stratospheric change. J. Environ. Monit., 6, 721, https://doi.org/10.1039/b404256e.

— , and Coauthors, 2011: An evaluation of uncertainties in monitoring middle atmosphere temperatures with the ground-based lidar network in support of space observations. J. Atmos. Sol.-Terr. Phys., 73, 627-642, https://doi.org/10.1016/j.jastp.2011.01.003.

Khaykin, S. M., and Coauthors, 2017: Postmillennium changes in stratospheric temperature consistently resolved by GPS radio occultation and AMSU observations. Geophys. Res. Lett., 44, 7510-7518, https://doi.org/10.1002/2017GL074353.

Kursinski, E. R., and T. Gebhardt, 2014: A method to deconvolve errors in GPS RO-derived water vapor histograms. J. Atmos. Oceanic Technol., 31, 2606-2628, https://doi.org/10.1175/JTECHD-13-00233.1.

— , G. A. Hajj, K. R. Hardy, L. J. Romans, and J. T. Schofield, 1995: Observing tropospheric water vapor by radio occultation using the Global Positioning System. Geophys. Res. Lett., 22, 2365-2368, https://doi.org/10.1029/95GL02127.

— — - J. T. Schofield, R. P. Linfield, and K. R. Hardy, 1997: Observing Earth's atmosphere with radio occultation measurements using the Global Positioning System. J. Geophys. Res., 102, 23 429-23 465, https://doi.org/10.1029/97JD01569.

Lackner, B. C., A. K. Steiner, G. Kirchengast, and G. C. Hegerl, 2011: Atmospheric climate change detection by radio occul- tation data using a fingerprinting method. J. Climate, 24, 52755291, https://doi.org/10.1175/2011JCLI3966.1.

Ladstädter, F., A. K. Steiner, U. Foelsche, L. Haimberger, C. Tavolato, and G. Kirchengast, 2011: An assessment of differences in lower stratospheric temperature records from (A) MSU, radiosondes, and GPS radio occultation. Atmos. Meas. Tech., 4, 1965-1977, https://doi.org/10.5194/amt-4-1965-2011.

M. Schwärz, and G. Kirchengast, 2015: Climate intercomparison of GPS radio occultation, RS90/92 radiosondes and GRUAN from 2002 to 2013. Atmos. Meas. Tech., 8, 18191834, https://doi.org/10.5194/amt-8-1819-2015.

Lanzante, J. R., S. A. Klein, and D. J. Seidel, 2003: Temporal homogenization of monthly radiosonde temperature data. Part I: Methodology. J. Climate, 16, 224-240, https://doi.org/10.1175/ 1520-0442(2003)016<0224:THOMRT >2.0.CO;2.

Leblanc, T., and I. S. McDermid, 2001: Quasi-biennial oscillation signatures in ozone and temperature observed by lidar at Mauna Loa, Hawaii $\left(19.5^{\circ} \mathrm{N}, 155.6^{\circ} \mathrm{W}\right)$. J. Geophys. Res., 106, 14 869-14 874, https://doi.org/10.1029/2001JD900162.

, - P. Keckhut, A. Hauchecorne, C. Y. She, and D. A. Krueger, 1998: Temperature climatology of the middle atmosphere from long-term lidar measurements at middle and low latitudes. J. Geophys. Res., 103, 17 191-17204, https:// doi.org/10.1029/98JD01347.

, R. J. Sica, J. A. E. van Gijsel, A. Haefele, G. Payen, and G. Liberti, 2016: Proposed standardized definitions for vertical resolution and uncertainty in the NDACC lidar ozone and temperature algorithms-Part 3: Temperature uncertainty budget. Atmos. Meas. Tech., 9, 4079-4101, https://doi.org/ 10.5194/amt-9-4079-2016.

Leroy, S. S., J. G. Anderson, and J. A. Dykema, 2006: Climate benchmarking using GNSS occultation. Atmosphere and Climate: Studies by Occultation Methods, U. Foelsche, G. Kirchengast, and A. Steiner, Eds., Springer-Verlag, 287-301.

, C. O. Ao, and O. P. Verkhoglyadova, 2018: Temperature trends and anomalies in modern satellite data: Infrared sounding and GPS radio occultation. J. Geophys. Res. Atmos., 123, 11 431-11 444, https://doi.org/10.1029/2018JD028990.

Li, T., T. Leblanc, I. S. McDermid, P. Keckhut, A. Hauchecorne, and X. Dou, 2011: Middle atmosphere temperature trend and solar cycle revealed by long-term Rayleigh lidar observations. J. Geophys. Res., 116, D00P05, https://doi.org/10.1029/2010JD015275.

Lott, F. C., P. A. Stott, D. M. Mitchell, N. Christidis, N. P. Gillett, L. Haimberger, J. Perlwitz, and P. W. Thorne, 2013: Models versus radiosondes in the free atmosphere: A new detection and attribution analysis of temperature. J. Geophys. Res. Atmos., 118, 2609-2619, https://doi.org/10.1002/jgrd.50255.

Maycock, A. C., and Coauthors, 2018: Revisiting the mystery of recent stratospheric temperature trends. Geophys. Res. Lett., 45, 9919-9933, https://doi.org/10.1029/2018GL078035.

McCarthy, M. P., H. A. Titchner, P. W. Thorne, S. F. B. Tett, L. Haimberger, and D. E. Parker, 2008: Assessing bias and uncertainty in the HadAT-adjusted radiosonde climate record. J. Climate, 21, 817-832, https://doi.org/10.1175/2007JCLI1733.1.

McLandress, C., T. G. Shepherd, A. I. Jonsson, T. von Clarmann, and B. Funke, 2015: A method for merging nadir-sounding climate records, with an application to the global-mean stratospheric temperature data sets from SSU and AMSU. Atmos. Chem. Phys., 15, 9271-9284, https://doi.org/10.5194/acp-15-9271-2015.

Mears, C. A., and F. J. Wentz, 2009a: Construction of the remote sensing systems V3.2 atmospheric temperature records from the MSU and AMSU microwave sounders. J. Atmos. Oceanic Technol., 26, 10401056, https://doi.org/10.1175/2008JTECHA1176.1. 
, and 2009b: Construction of the RSS V3.2 lowertropospheric temperature dataset from the MSU and AMSU microwave sounders. J. Atmos. Oceanic Technol., 26, 14931509, https://doi.org/10.1175/2009JTECHA1237.1.

, and _ - 2016: Sensitivity of satellite-derived tropospheric temperature trends to the diurnal cycle adjustment. J. Climate, 29, 3629-3646, https://doi.org/10.1175/JCLI-D15-0744.1.

- , and 2017: A satellite-derived lower-tropospheric atmospheric temperature dataset using an optimized adjustment for diurnal effects. J. Climate, 30, 7695-7718, https://doi.org/ 10.1175/JCLI-D-16-0768.1.

,,-- P. Thorne, and D. Bernie, 2011: Assessing uncertainty in estimates of atmospheric temperature changes from MSU and AMSU using a Monte-Carlo estimation technique. J. Geophys. Res., 116, D08112, https://doi.org/10.1029/ 2010JD014954.

Melbourne, W. G., and Coauthors, 1994: The application of spaceborne GPS to atmospheric limb sounding and global change monitoring. Jet Propulsion Laboratory Publ. 94-18, 147 pp., https://ntrs.nasa.gov/archive/nasa/casi.ntrs.nasa.gov/ 19960008694.pdf.

Mitchell, D. M., P. W. Thorne, P. A. Stott, and L. J. Gray, 2013: Revisiting the controversial issue of tropical tropospheric temperature trends. Geophys. Res. Lett., 40, 2801-2806, https://doi.org/10.1002/grl.50465.

Morice, C. P., J. J. Kennedy, N. A. Rayner, and P. D. Jones, 2012: Quantifying uncertainties in global and regional temperature change using an ensemble of observational estimates: The HadCRUT4 data set. J. Geophys. Res., 117, D08101, https:// doi.org/10.1029/2011JD017187.

Nash, J., and R. Saunders, 2013: A review of Stratospheric Sounding Unit radiance observations in support of climate trends investigations and reanalysis. Met Office Forecasting Research Tech. Rep. 586, 58 pp., https://library.metoffice.gov.uk/ Portal/DownloadImageFile.ashx?objectId=433.

— and 2015: A review of Stratospheric Sounding Unit radiance observations for climate trends and reanalyses. Quart. J. Roy. Meteor. Soc., 141, 2103-2113, https://doi.org/ 10.1002/qj.2505.

— T. Takley, H. Vömel, and L. Wei, 2011: WMO intercomparison of high quality radiosonde systems: Yangjiang, China, 12 July3 August 2010. WMO Instruments and Observing Methods Rep. 107, 249 pp., https://ibrary.wmo.int/doc_num.php?explnum_id=9467.

Natural Resources Canada, 2019: Solar radio flux-Daily flux values. NRC, accessed 1 November 2019, https:/www.spaceweather.gc.ca/ solarflux/sx-5-en.php.

Naujokat, B., 1986: An update of the observed quasi-biennial oscillation of the stratospheric winds over the tropics. J. Atmos. Sci., 43, 1873-1877, https://doi.org/10.1175/1520-0469(1986) 043<1873:AUOTOQ > 2.0.CO;2.

NDACC, 2019: Lidar temperatures from DWD HOH, JPL TMF, JPL MLO. Network for the Detection of Atmospheric Composition Change, accessed 1 November 2019, http:// www.ndacc.org.

Newman, P. A., and E. R. Nash, 2005: The unusual Southern Hemisphere stratosphere winter of 2002. J. Atmos. Sci., 62, 614-628, https://doi.org/10.1175/JAS-3323.1.

NOAA NCEI, 2019: Radiosonde Atmospheric Temperature Products for Assessing Climate (RATPAC) Version 2. NOAA/National Centers for Environmental Information, accessed 1 November 2019, https://www.ncdc.noaa.gov/data-access/weather-balloon/ radiosonde-atmospheric-temperature-products-accessing-climate.
NOAA STAR, 2019: STAR microwave sounding calibration and trends. NOAA, accessed 1 November 2019, https:/www.star.nesdis.noaa.gov/ smcd/emb/mscat.

Po-Chedley, S., and Q. Fu, 2012a: Discrepancies in tropical upper tropospheric warming between atmospheric circulation models and satellites. Environ. Res. Lett., 7, 044018, https://doi.org/ 10.1088/1748-9326/7/4/044018.

— and - 2012b: A bias in the midtropospheric channel warm target factor on the NOAA-9 Microwave Sounding Unit. J. Atmos. Oceanic Technol., 29, 646-652, https://doi.org/10.1175/ JTECH-D-11-00147.1.

_ , T. J. Thorsen, and Q. Fu, 2015: Removing diurnal cycle contamination in satellite-derived tropospheric temperatures: Understanding tropical tropospheric trend discrepancies. $J$. Climate, 28, 2274-2290, https://doi.org/10.1175/JCLI-D-13-00767.1.

Polvani, L. M., L. Wang, V. Aquila, and D. W. Waugh, 2017: The impact of ozone-depleting substances on tropical upwelling, as revealed by the absence of lower-stratospheric cooling since the late 1990s J. Climate, 30, 2523-2534, https://doi.org/10.1175/JCLI-D-16-0532.1.

Ramaswamy, V., and Coauthors, 2001: Stratospheric temperature trends: Observations and model simulations. Rev. Geophys. 39, 71-122, https://doi.org/10.1029/1999RG000065.

—, M. D. Schwarzkopf, W. J. Randel, B. D. Santer, B. J. Soden, and G. L. Stenchikov, 2006: Anthropogenic and natural influences in the evolution of lower stratospheric cooling. Science, 311, 1138-1141, https://doi.org/10.1126/science.1122587.

Randel, W. J., F. Wu, R. Swinbank, J. Nash, and A. O'Neill, 1999: Global QBO circulation derived from UKMO stratospheric analyses. J. Atmos. Sci., 56, 457-474, https://doi.org/10.1175/ 1520-0469(1999)056<0457:GQCDFU>2.0.CO;2.

— , and Coauthors, 2009: An update of observed stratospheric temperature trends. J. Geophys. Res., 114, D02107, https:/ doi.org/10.1029/2008JD010421.

— A. K. Smith, F. Wu, C.-Z. Zou, and H. Qian, 2016: Stratospheric temperature trends over 1979-2015 derived from combined SSU, MLS and SABER satellite observations. J. Climate, 29, 48434859, https://doi.org/10.1175/JCLI-D-15-0629.1.

_ L. Polvani, F. Wu, D. E. Kinnison, C.-Z. Zou, and C. Mears, 2017: Troposphere-stratosphere temperature trends derived from satellite data compared with ensemble simulations from WACCM. J. Geophys. Res. Atmos., 122, 9651-9667, https:// doi.org/10.1002/2017JD027158.

Remsberg, E. E., and Coauthors, 2008: Assessment of the quality of the version 1.07 temperature-versus-pressure profiles of the middle atmosphere from TIMED/SABER. J. Geophys. Res., 113, D17101, https://doi.org/10.1029/2008JD010013.

Robock, A., 2000: Volcanic eruptions and climate. Rev. Geophys., 38, 191-219, https://doi.org/10.1029/1998RG000054.

ROM SAF, 2019: ROM SAF radio occultation product. EUMETSAT, accessed 1 November 2019, http://www.romsaf.org.

RSS, 2019: Microwave sounding data products from RSS. Remote Sensing Systems, accessed 1 November 2019, http://www.remss.com/ measurements/upper-air-temperature.

Santer, B. D., and Coauthors, 2001: Accounting for the effects of volcanoes and ENSO in comparisons of modeled and observed temperature trends. J. Geophys. Res., 106, 28033 28 059, https://doi.org/10.1029/2000JD000189.

_ - and Coauthors, 2005: Amplification of surface temperature trends and variability in the tropical atmosphere. Science, $\mathbf{3 0 9}$, 1551-1556, https://doi.org/10.1126/science.1114867.

— , and Coauthors, 2008: Consistency of modelled and observed temperature trends in the tropical troposphere. Int. J. Climatol., 28, 1703-1722, https://doi.org/10.1002/joc.1756. 
_- and Coauthors, 2013: Human and natural influences on the changing thermal structure of the atmosphere. Proc. Natl. Acad. Sci. USA, 110, 17235-17240, https://doi.org/10.1073/ pnas. 1305332110.

_ _ and Coauthors, 2017a: Causes of differences in model and satellite tropospheric warming rates. Nat. Geosci., 10, 478-485, https://doi.org/10.1038/ngeo2973.

— climate models and satellite data. J. Climate, 30, 373-392, https://doi.org/10.1175/JCLI-D-16-0333.1.

_ J. C. Fyfe, S. Solomon, J. F. Painter, C. Bonfils, G. Pallotta, and M. D. Zelinka, 2019: Quantifying stochastic uncertainty in detection time of human-caused climate signals. Proc. Natl. Acad. Sci. USA, 116, 19821-19827, https://doi.org/10.1073/ pnas.1904586116.

Scherllin-Pirscher, B., G. Kirchengast, A. K. Steiner, Y.-H. Kuo, and U. Foelsche, 2011a: Quantifying uncertainty in climatological fields from GPS radio occultation: An empiricalanalytical error model. Atmos. Meas. Tech., 4, 2019-2034, https://doi.org/10.5194/amt-4-2019-2011.

_ A. K. Steiner, G. Kirchengast, Y.-H. Kuo, and U. Foelsche, 2011b: Empirical analysis and modeling of errors of atmospheric profiles from GPS radio occultation. Atmos. Meas. Tech., 4, 1875-1890, https://doi.org/10.5194/amt-4-1875-2011.

, C. Deser, S.-P. Ho, C. Chou, W. Randel, and Y.-H. Kuo, 2012: The vertical and spatial structure of ENSO in the upper troposphere and lower stratosphere from GPS radio occultation measurements. Geophys. Res. Lett., 39, L20801, https://doi.org/ 10.1029/2012GL053071.

— 2017: The power of vertical geolocation of atmospheric profiles from GNSS radio occultation. J. Geophys. Res. Atmos., 122, 1595-1616, https://doi.org/10.1002/2016JD025902.

Schwartz, M. J., and Coauthors, 2008: Validation of the Aura microwave limb sounder temperature and geopotential height measurements. J. Geophys. Res., 113, D15S11, https://doi.org/ 10.1029/2007JD008783.

Seidel, D. J., and Coauthors, 2009: Reference upper-air observations for climate: Rationale, progress, and plans. Bull. Amer. Meteor. Soc., 90, 361-369, https://doi.org/10.1175/2008BAMS2540.1.

_ N. N. P. Gillett, J. R. Lanzante, K. P. Shine, and P. W. Thorne, 2011: Stratospheric temperature trends: Our evolving understanding. Wiley Interdiscip. Rev.: Climate Change, 2, 592-616, https://doi.org/10.1002/wcc.125.

__ , and Coauthors, 2016: Stratospheric temperature changes during the satellite era. J. Geophys. Res. Atmos., 121, 664-681, https://doi.org/10.1002/2015JD024039.

Shangguan, M., W. Wang, and S. Jin, 2019: Variability of temperature and ozone in the upper troposphere and lower stratosphere from multi-satellite observations and reanalysis data. Atmos. Chem. Phys., 19, 6659-6679, https://doi.org/10.5194/ acp-19-6659-2019.

Sherwood, S. C., and N. Nishant, 2015: Atmospheric changes through 2012 as shown by iteratively homogenized radiosonde temperature and wind data (IUKv2). Environ. Res. Lett., 10, 054007, https://doi.org/10.1088/1748-9326/10/5/054007.

_ - J. R. Lanzante, and C. L. Meyer, 2005: Radiosonde daytime biases and late-20th century warming. Science, 309, 1556-1559, https://doi.org/10.1126/science. 1115640 .

, C. L. Meyer, R. J. Allen, and H. A. Titchner, 2008: Robust tropospheric warming revealed by iteratively homogenized radiosonde data. J. Climate, 21, 5336-5352, https://doi.org/ 10.1175/2008JCLI2320.1.
Shine, K. P., and Coauthors, 2003: A comparison of model-simulated trends in stratospheric temperatures. Quart. J. Roy. Meteor. Soc., 129, 1565-1588, https://doi.org/10.1256/qj.02.186.

— J. J. Barnett, and W. J. Randel, 2008: Temperature trends derived from Stratospheric Sounding Unit radiances: The effect of increasing $\mathrm{CO}_{2}$ on the weighting function. Geophys. Res. Lett., 35, L02710, https://doi.org/10.1029/2007GL032218.

Simmons, A. J., and Coauthors, 2020: Global stratospheric temperature bias and other stratospheric aspects of ERA5 and ERA5.1. ECMWF Tech. Memo. 859, accessed 13 April 2020, 40 pp., https://www.ecmwf.int/node/19362.

Sofieva, V. F., F. Dalaudier, A. Hauchecorne, and V. Kan, 2019: High-resolution temperature profiles retrieved from bichromatic stellar scintillation measurements by GOMOS/Envisat. Atmos. Meas. Tech., 12, 585-598, https://doi.org/10.5194/amt12-585-2019.

Solomon, S., J. S. Daniel, R. R. Neely, J.-P. Vernier, E. G. Dutton, and L. W. Thomason, 2011: The persistently variable "background" stratospheric aerosol layer and global climate change. Science, 333, 866-870, https://doi.org/10.1126/science.1206027.

— , P. J. Young, and B. Hassler, 2012: Uncertainties in the evolution of stratospheric ozone and implications for recent temperature changes in the tropical lower stratosphere. Geophys. Res. Lett., 39, L17706, https://doi.org/10.1029/2012GL052723.

, D. J. Ivy, D. Kinnison, M. J. Mills, R. R. Neely, and A. Schmidt, 2016: Emergence of healing in the Antarctic ozone layer. Science, 353, 269-274, https://doi.org/10.1126/ science.aae0061.

— - and Coauthors, 2017: Mirrored changes in Antarctic ozone and stratospheric temperature in the late 20 th versus early $21 \mathrm{st}$ centuries. J. Geophys. Res. Atmos., 122, 8940-8950, https:// doi.org/10.1002/2017JD026719.

Spencer, R. W., J. R. Christy, and W. D. Braswell, 2017: UAH version 6 global satellite temperature products: Methodology and results. Asia-Pac. J. Atmos. Sci., 53, 121-130, https:// doi.org/10.1007/s13143-017-0010-y.

Steinbrecht, W., H. Claude, F. Schönenborn, U. Leiterer, H. Dier, and E. Lanzinger, 2008: Pressure and temperature differences between Vaisala RS80 and RS92 radiosonde systems. J. Atmos. Oceanic Technol., 25, 909-927, https://doi.org/10.1175/2007JTECHA999.1.

_ , and Coauthors, 2009: Ozone and temperature trends in the upper stratosphere at five stations of the Network for the Detection of Atmospheric Composition Change. Int. J. Remote Sens., 30, 38753886, https://doi.org/10.1080/01431160902821841.

Steiner, A. K., G. Kirchengast, M. Borsche, U. Foelsche, and T. Schoengassner, 2007: A multi-year comparison of lower stratospheric temperatures from CHAMP radio occultation data with MSU/AMSU records. J. Geophys. Res., 112, D22110, https://doi.org/10.1029/2006JD008283.

- — B. C. Lackner, B. Pirscher, M. Borsche, and U. Foelsche, 2009: Atmospheric temperature change detection with GPS radio occultation 1995 to 2008. Geophys. Res. Lett., 36, L18702, https://doi.org/10.1029/2009GL039777.

_ B. C. Lackner, F. Ladstädter, B. Scherllin-Pirscher, U. Foelsche, and G. Kirchengast, 2011: GPS radio occultation for climate monitoring and change detection. Radio Sci., 46, RS0D24, https:// doi.org/10.1029/2010RS004614.

-, and Coauthors, 2013: Quantification of structural uncertainty in climate data records from GPS radio occultation. Atmos. Chem. Phys., 13, 1469-1484, https://doi.org/10.5194/acp-13-1469-2013. , and Coauthors, 2020: Consistency and structural uncertainty of multi-mission GPS radio occultation records. Atmos. Meas. Tech., 13, 2547-2575, https://doi.org/10.5194/amt-2019-358. 
Stocker, M., F. Ladstädter, H. Wilhelmsen, and A. K. Steiner, 2019: Quantifying stratospheric temperature signals and climate imprints from post-2000 volcanic eruptions. Geophys. Res. Lett., 46, 12 486-12 494, https://doi.org/10.1029/2019GL084396.

Stone, P. H., and J. H. Carlson, 1979: Atmospheric lapse rate regimes and their parameterization. J. Atmos. Sci., 36, 415-423, https:// doi.org/10.1175/1520-0469(1979)036<0415:ALRRAT>2.0.CO;2.

Suárez-Gutiérrez, L., C. Li, P. W. Thorne, and J. Marotzke, 2017: Internal variability in simulated and observed tropical tropospheric temperature trends. Geophys. Res. Lett., 44, 57095719, https://doi.org/10.1002/2017GL073798.

Thomason, L. W., 2017: GloSSAC Level 3 netCDF file, version 1. NASA, accessed 1 November 2019, https://doi.org/10.5067/ GLOSSAC-L3-V1.0.

—_, and Coauthors, 2018: A global space-based stratospheric aerosol climatology: 1979-2016. Earth Syst. Sci. Data, 10, 469492, https://doi.org/10.5194/essd-10-469-2018.

Thompson, D. W. J., and Coauthors, 2012: The mystery of recent stratospheric temperature trends. Nature, 491, 692-697, https:// doi.org/10.1038/nature11579.

Thorne, P. W., 2005: Revisiting radiosonde upper air temperatures from 1958 to 2002. J. Geophys. Res., 110, D18105, https:// doi.org/10.1029/2004JD005753.

, and Coauthors, 2011: A quantification of uncertainties in historical tropical tropospheric temperature trends from radiosondes. J. Geophys. Res., 116, D12116, https://doi.org/ 10.1029/2010JD015487.

—_, and Coauthors, 2013: GCOS reference upper air network (GRUAN): Steps towards assuring future climate records. AIP Conf. Proc., 1552, 1042-1047, https://doi.org/10.1063/1.4821421.

Titchner, H. A., P. W. Thorne, M. P. McCarthy, S. F. B. Tett, L. Haimberger, and D. E. Parker, 2009: Critically reassessing tropospheric temperature trends from radiosondes using realistic validation experiments. J. Climate, 22, 465-485, https:// doi.org/10.1175/2008JCLI2419.1.

Tradowsky, J. S., G. E. Bodeker, R. R. Querel, P. J. H. Builtjes, and J. Fischer, 2018: Combining data from the distributed GRUAN site Lauder-Invercargill, New Zealand, to provide a site atmospheric state best estimate of temperature. Earth Syst. Sci. Data, 10, 2195-2211, https://doi.org/10.5194/essd-10-2195-2018.

Trenberth, K. E., 1997: The definition of El Niño. Bull. Amer. Meteor. Soc., 78, 2771-2778, https://doi.org/10.1175/1520-0477(1997)078<2771: TDOENO $>2.0 . \mathrm{CO} ; 2$

- , and Coauthors, 2013: Challenges of a sustained climate observing system. Climate Science for Serving Society, G. R. Asrar and J. W. Hurrell, Eds., Springer, 13-50.

Tuel, A., 2019: Explaining differences between recent model and satellite tropospheric warming rates with tropical SSTs. Geophys. Res. Lett., 46, 9023-9030, https://doi.org/10.1029/2019GL083994.

UAH, 2019: UAH microwave sounding data v6.0. National Space Science and Technology Center, accessed 1 November 2019, https://www.nsstc.uah.edu/data/msu/v6.0.

UCAR CDAAC, 2019: UCAR CDAAC radio occultation data. UCAR, accessed 1 November 2019, http://cdaac-www.cosmic.ucar.edu.

Wallace, J. M., R. L. Panetta, and J. Estberg, 1993: Representation of the equatorial stratospheric quasi-biennial oscillation in EOF phase space. J. Atmos. Sci., 50, 1751-1762, https://doi.org/ 10.1175/1520-0469(1993)050<1751:ROTESQ > 2.0.CO;2.

Wang, L., C.-Z. Zou, and H. Qian, 2012: Construction of stratospheric temperature data records from Stratospheric Sounding
Units. J. Climate, 25, 2931-2946, https://doi.org/10.1175/JCLID-11-00350.1.

Wang, W., and C.-Z. Zou, 2014: AMSU-A-only atmospheric temperature data records from the lower troposphere to the top of the stratosphere. J. Atmos. Oceanic Technol., 31, 808825, https://doi.org/10.1175/JTECH-D-13-00134.1.

Wentz, F. J., and M. Schabel, 1998: Effects of orbital decay on satellitederived lower-tropospheric temperature trends. Nature, 394, 661664, https://doi.org/10.1038/29267.

Werner, J., K. W. Rothe, and H. Walther, 1983: Monitoring of the stratospheric ozone layer by laser radar. Appl. Phys., 32B, 113-118, https://doi.org/10.1007/BF00688815.

Wilhelmsen, H., F. Ladstädter, B. Scherllin-Pirscher, and A. K. Steiner, 2018: Atmospheric QBO and ENSO indices with high vertical resolution from GNSS radio occultation temperature measurements. Atmos. Meas. Tech., 11, 1333-1346, https:// doi.org/10.5194/amt-11-1333-2018.

Wing, R., A. Hauchecorne, P. Keckhut, S. Godin-Beekmann, S. Khaykin, E. M. McCullough, J.-F. Mariscal, and É. d'Almeida, 2018a: Lidar temperature series in the middle atmosphere as a reference data set-Part 1: Improved retrievals and a 20-year cross-validation of two co-located French lidars. Atmos. Meas. Tech., 11, 5531-5547, https:// doi.org/10.5194/amt-11-5531-2018.

and $\longrightarrow, 2018 \mathrm{~b}$ : Lidar temperature series in the middle atmosphere as a reference data set-Part 2: Assessment of temperature observations from MLS/Aura and SABER/TIMED satellites. Atmos. Meas. Tech., 11, 67036717, https://doi.org/10.5194/amt-11-6703-2018.

WMO, 2018: Scientific assessment of ozone depletion: 2018. Global Ozone Research and Monitoring Project Rep. 58, https:// www.esrl.noaa.gov/csd/assessments/ozone/2018

Zeng, Z., S. Sokolovskiy, W. S. Schreiner, and D. Hunt, 2019: Representation of vertical atmospheric structures by radio occultation observations in the upper troposphere and lower stratosphere: Comparison to high-resolution radiosonde profiles. J. Atmos. Oceanic Technol., 36, 655-670, https://doi.org/ 10.1175/JTECH-D-18-0105.1.

Zou, C.-Z., and W. Wang, 2010: Stability of the MSU-derived atmospheric temperature trend. J. Atmos. Oceanic Technol., 27, 1960-1971, https://doi.org/10.1175/2009JTECHA1333.1.

— , and — 2011: Intersatellite calibration of AMSU-A observations for weather and climate applications. J. Geophys. Res., 116, D23113, https://doi.org/10.1029/2011JD016205.

— record from merged SSU and AMSU-A observations. J. Atmos. Oceanic Technol., 33, 1967-1984, https://doi.org/10.1175/JTECHD-16-0018.1.

— M. Gao, and M. D. Goldberg, 2009: Error structure and atmospheric temperature trends in observations from the Microwave Sounding Unit. J. Climate, 22, 1661-1681, https:// doi.org/10.1175/2008JCLI2233.1.

, H. Qian, W. Wang, L. Wang, and C. Long, 2014: Recalibration and merging of SSU observations for stratospheric temperature trend studies. J. Geophys. Res. Atmos., 119, 13 180-13 205, https:// doi.org/10.1002/2014JD021603.

— M. D. Goldberg, and X. Hao, 2018: New generation of U.S. satellite microwave sounder achieves high radiometric stability performance for reliable climate change detection. Sci. $A d v .$, 4, eaau0049, https://doi.org/10.1126/sciadv.aau0049. 